\title{
WestVirginiaUniversity
}

THE RESEARCH REPOSITORY @ WVU

Graduate Theses, Dissertations, and Problem Reports

2004

\section{Use of a token economy to increase exercise in children with cystic fibrosis}

\author{
Rebecca S. Bernard \\ West Virginia University
}

Follow this and additional works at: https://researchrepository.wvu.edu/etd

\section{Recommended Citation}

Bernard, Rebecca S., "Use of a token economy to increase exercise in children with cystic fibrosis" (2004). Graduate Theses, Dissertations, and Problem Reports. 2107.

https://researchrepository.wvu.edu/etd/2107

This Dissertation is protected by copyright and/or related rights. It has been brought to you by the The Research Repository @ WVU with permission from the rights-holder(s). You are free to use this Dissertation in any way that is permitted by the copyright and related rights legislation that applies to your use. For other uses you must obtain permission from the rights-holder(s) directly, unless additional rights are indicated by a Creative Commons license in the record and/ or on the work itself. This Dissertation has been accepted for inclusion in WVU Graduate Theses, Dissertations, and Problem Reports collection by an authorized administrator of The Research Repository @ WVU.

For more information, please contact researchrepository@mail.wvu.edu. 
Use of a Token Economy to Increase Exercise in Children with Cystic Fibrosis

Rebecca S. Bernard

\begin{abstract}
Dissertation submitted to the
College of Arts and Sciences

at West Virginia University

in partial fulfillment of the requirements

for the degree of
\end{abstract}

\author{
Doctor of Philosophy \\ in \\ Psychology
}

\author{
Lindsey L. Cohen, Ph.D., Chair \\ Cynthia M. Anderson, Ph.D. \\ William J. Fremouw, Ph.D. \\ Cheryl B. McNeil, Ph.D. \\ Kathryn S. Moffett, M.D. \\ Department of Psychology
}

Morgantown, West Virginia
2004

Keywords: Token Economy, Cystic Fibrosis, Exercise, Children

Copyright 2004 Rebecca S. Bernard 


\begin{abstract}
Use of a Token Economy to Increase Exercise in Children with Cystic Fibrosis
\end{abstract}

\title{
Rebecca S. Bernard
}

Cystic fibrosis is a chronic illness that affects several major organ systems, primarily the respiratory system and the exocrine glands of the pancreatic system. The treatment regimen is extensive (e.g., medications, vitamins, high fat diet, airway clearance sessions). Although adherence to medications is high, adherence to the airway clearance techniques (chest physiotherapy and exercise) is less consistent. Increasing exercise adherence is of utmost importance because pulmonary difficulties are associated with the highest mortality rate and exercise is more beneficial than other airway clearance methods. Despite this, very little research has focused on increasing exercise adherence in this population. The purpose of this study was to examine the effectiveness of a token economy on increasing aerobic exercise in children with cystic fibrosis. As predicted, the token economy increased exercise for all three participants. Mixed results were found for the effects of regular exercise on participant's quality of life and attitudes towards exercise. Finally, regular exercise did not negatively impact the participants' pulmonary functioning or fitness level and participants demonstrated increased body fat percentage with one participant demonstrating increased body mass index as well. Treatment implications and recommendations for future research are discussed. 


\section{Dedication}

This manuscript is dedicated to my wonderful parents, Bruce Bernard and Cheryl Palpant, who have always encouraged me to seek out my dreams, supported me along the way, and never doubted that I would achieve them. Thank you and I love you both. 


\section{Acknowledgements}

I owe many thanks to my advisor, Dr. Lindsey Cohen, who has supported me throughout my training, helped develop and refine my research skills, and been both a mentor and friend on campus and on the soccer field. I also would like to thank my other dissertation committee members, Dr. Cynthia Anderson, Dr. William Fremouw, Dr. Cheryl McNeil, and Dr. Kathryn Moffett for their expertise and guidance. Additionally, thanks are due to the staff at the Cystic Fibrosis Center, Dr. Anne Swisher and Linda Baer, for their unwavering support and enthusiasm for the study. Finally, I would like to thank my family for their faith and encouragement, my friends for helping me to keep things in perspective by reminding me of life outside of graduate school, and Chris Jacob for his patience and understanding and many attempts to decrease my often heightened stress level. 
Table of Contents

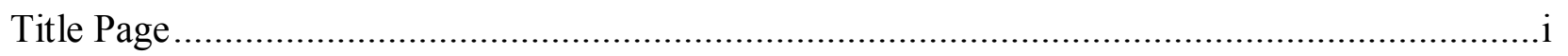

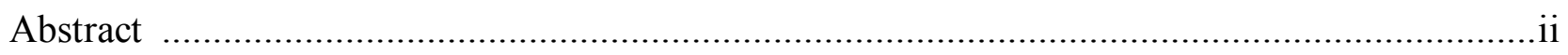

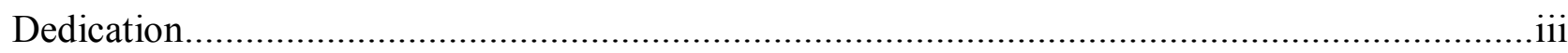

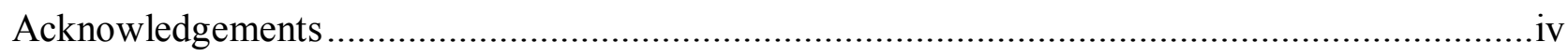

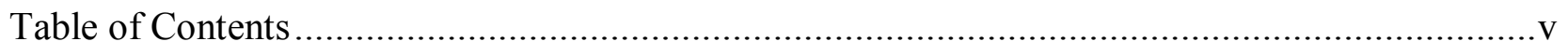

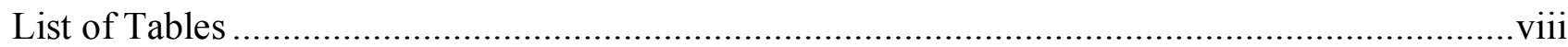

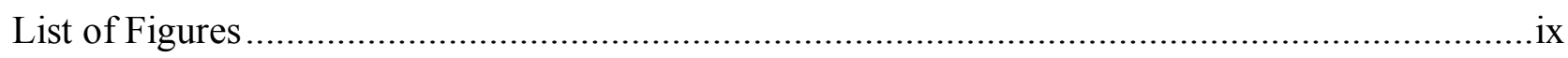

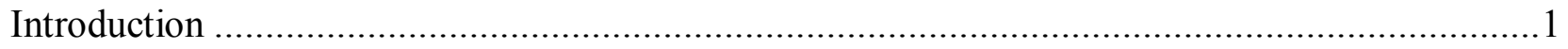

Treatment of Cystic Fibrosis..................................................................................

Adherence to Treatment Recommendations .......................................................

Treatment Adherence for Patients with Cystic Fibrosis.................................................5

Behavioral Techniques to Increase Adherence to Cystic Fibrosis Treatment ........................5

Adherence to Diet.......................................................................................... 6

Adherence to Airway Clearance Techniques ............................................................ 7

Increasing Exercise in Other Chronic Conditions ...............................................

Statement of the Problem ........................................................................................ 11

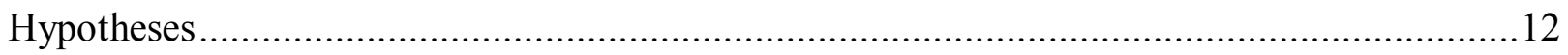

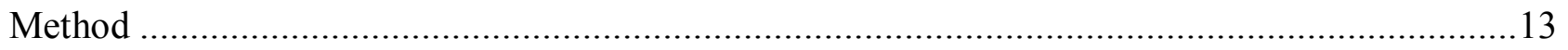

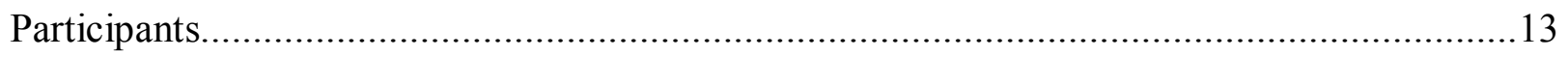

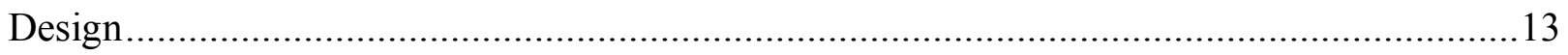

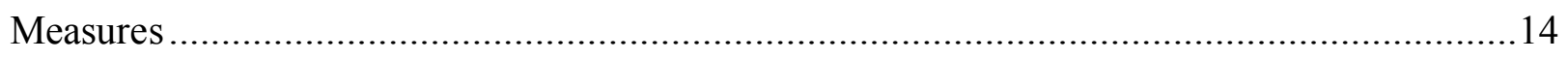

Background Information Form....................................................................... 14 


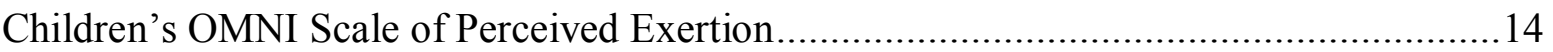

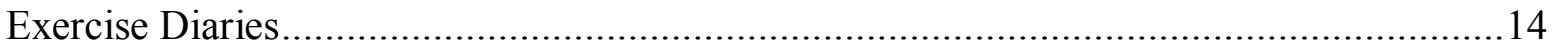

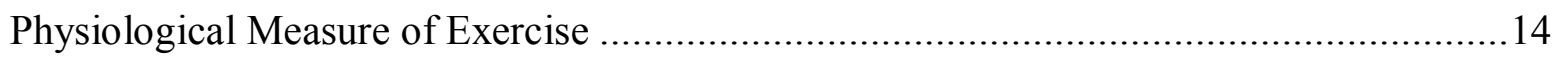

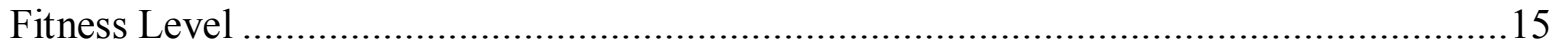

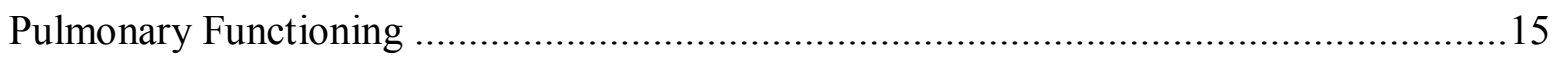

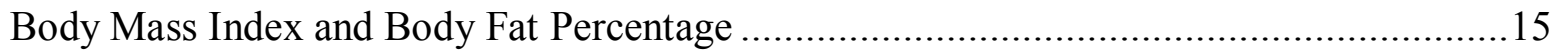

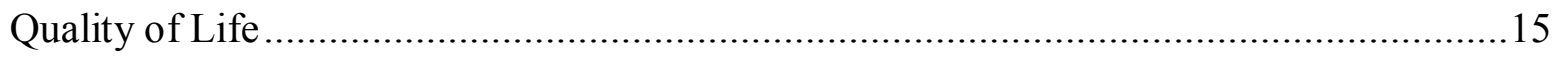

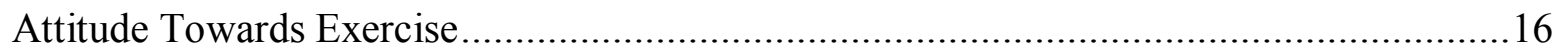

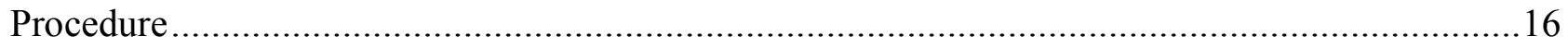

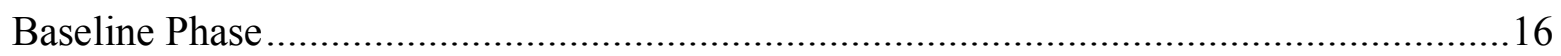

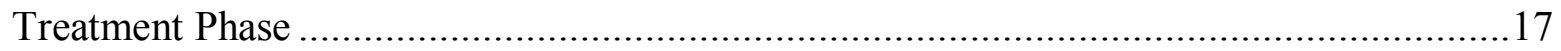

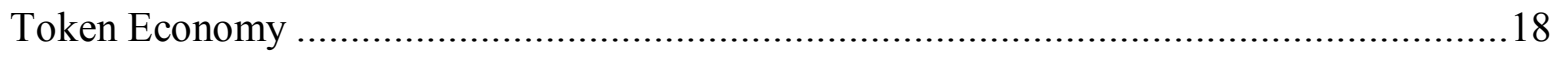

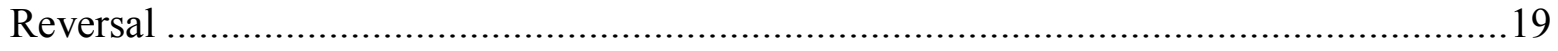

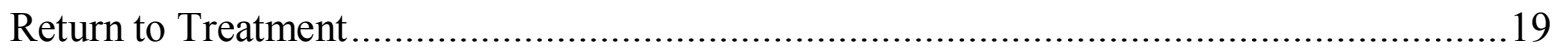

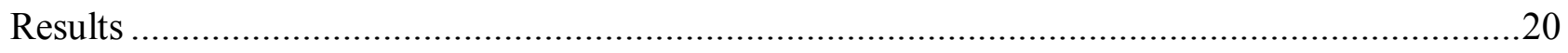

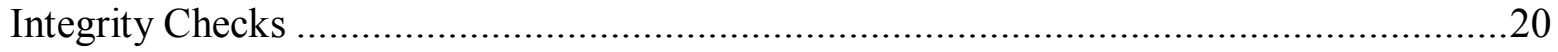

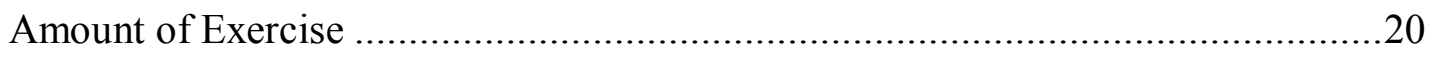

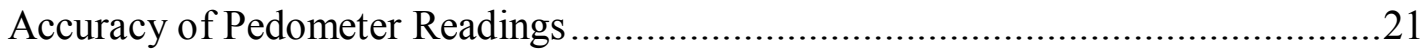

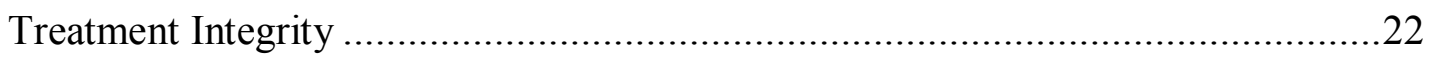

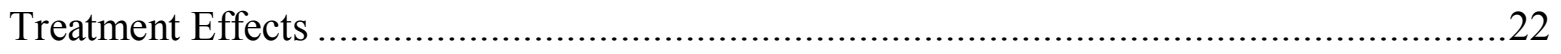

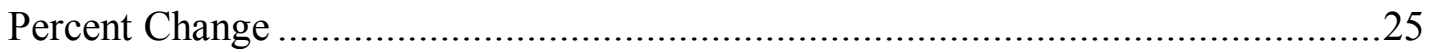

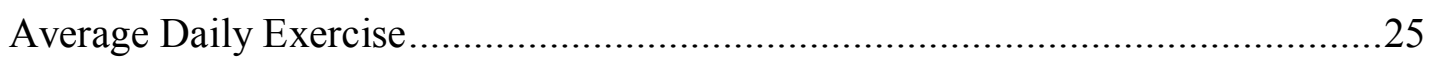

Average Days Exercised Per Week ………………..........................................26 
Medical Monitoring

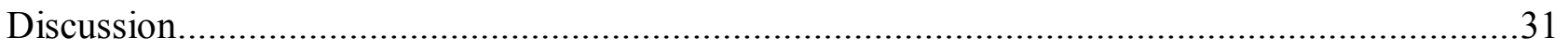

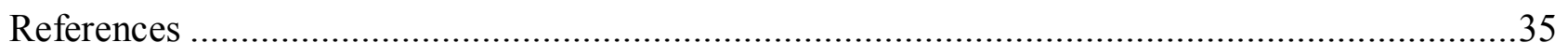

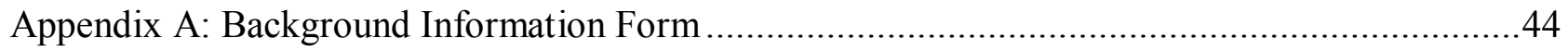

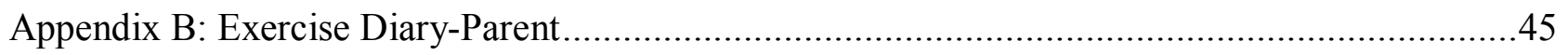

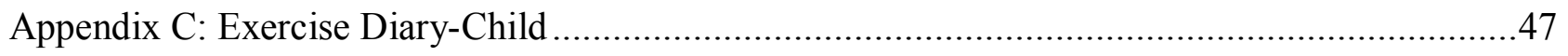

Appendix D: Children's Attitude Towards Exercise ...............................................................49

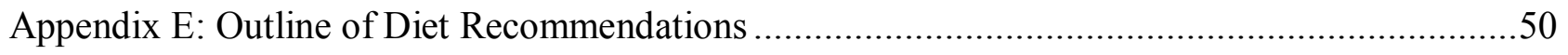

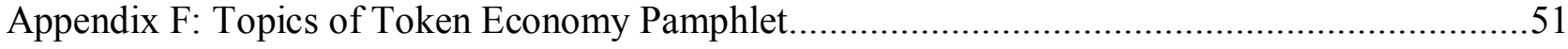

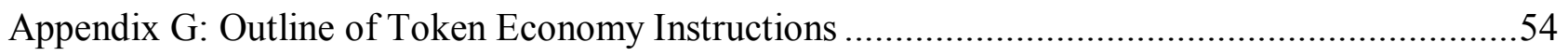

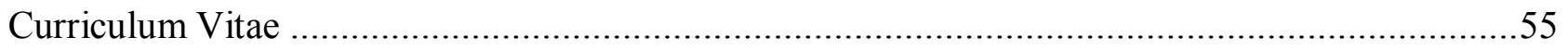




\section{List of Tables}

Table 1: Medical Monitoring Measure Scores at Pre- and Post-Treatment .................................27

Table 2: Mean Pre- and Post-Treatment PedsQL ${ }^{\mathrm{TM}} 4.0$ Scores ...............................................28

Table 3: VAS Scores across Phases for Amount Exercise is Enjoyed and Difficulty of Exercise ...30 


\section{List of Figures}

Figure 1. Results by phase of minutes exercised across days for Participant 1. Each data point on the graph represents the number of min exercised across two days

Figure 2. Results by phase of minutes exercised across days for Participant 2. Each data point on the graph represents the number of min exercised across two days ........................................23

Figure 3. Results by phase of minutes exercised across days for Participant 3. Each data point on the graph represents the number of min exercised across two days .......................................24

Figure 4. Average number of days exercised per week by phase for each participant ..................26 
Use of a Token Economy to Increase Exercise in Children with Cystic Fibrosis

Cystic fibrosis is the most common lethal hereditary disease among Caucasians and affects 1 in 2,500 births in the United States (Boas, 1997; FitzSimmons, 1993; Stark, Jelalian, \& Miller, 1995). Thirty thousand individuals in the United States currently suffer from cystic fibrosis and approximately 7 million individuals are non-symptomatic carriers of the disease. The presence of the disease itself is detected by elevated chloride levels during a sweat test (FitzSimmons). Most diagnoses are made during the first year of life and early symptoms include acute respiratory difficulties, malnutrition, and intestinal obstruction. Although the life expectancy has risen in the past decade, the current estimate of the median life expectancy is 30.1 years $(\mathrm{NIH}, 1997)$.

Cystic fibrosis causes the epithelia of many major organ systems (e.g., respiratory, digestive, reproductive, and pancreatic systems) to produce an abnormal, thick, viscous mucus (Boas, 1997; FitzSimmons, 1993; Stark et al., 1995). Although the disease causes serious complications in several major organs, the lungs and pancreas are the most profoundly affected and complications due to respiratory disease have the highest mortality rate (Marshall, Rosenfeld, \& Ramsey, 2000). In fact, researchers estimate that respiratory disease causes from $78 \%$ (FitzSimmons) to over $90 \%$ (Boas) of deaths associated with cystic fibrosis. Disease progression in the lungs begins with the accumulation of the abnormal mucus in the bronchi and bronchioles. This causes obstruction, which, in turn, causes bacteria to colonize and produce bacterial infection that results in permanent lung damage over time (Boas; Stark et al., 1995). A similar process occurs in the pancreas. The accumulation of abnormal mucus in the pancreas causes duct obstruction, which causes tissue damage and inadequate secretion of digestive enzymes. Due to these pancreatic deficits, approximately $85 \%$ of individuals with cystic fibrosis are pancreatic-insufficient. Specifically, they are unable to properly digest fat, fat-soluble vitamins, and protein, which ultimately lead to malnutrition (Boas; Stark et al., 1995).

Obviously, clearing the lungs of excess mucus and preventing malnutrition are essential to survival.

In the following sections, the current literature on treatment of the above-mentioned aspects of cystic fibrosis is discussed. First, general background information about the treatment of cystic fibrosis, reasons for non-adherence, and level of adherence for each component of the treatment regimen are reviewed. Next, literature examining behavioral techniques that have effectively increased regimen adherence in patients with cystic fibrosis and increased adherence to exercise regimens in other chronic conditions is presented.

\section{Treatment of Cystic Fibrosis}

Addressing pancreatic and pulmonary symptoms is important to longevity; thus, these symptoms are addressed immediately after diagnosis (Boas, 1997; Stark et al., 1995). Many individuals with cystic fibrosis are pancreatic-insufficient and require enzyme replacement supplements to help digest fat, protein, and vitamins (Elborn, 1998; Stark et al., 1995). Although enzyme supplements alleviate some of the problems related to pancreatic-insufficiency, most individuals with cystic fibrosis experience nutrient malabsorption, with 50\% falling below the $10^{\text {th }}$ percentile for their height, weight, or both (FitzSimmons, 1993). The problem of 
malabsorption is compounded by respiratory disease and a high metabolic rate; consequently children with cystic fibrosis should consume above the recommended daily allowance for children their age (MacDonald, Holden, \& Harris, 1991). In fact, children are instructed to consume $125-150 \%$ of the daily recommended allowance as well as take vitamin supplements to help negate the negative consequences of their digestive deficiencies. Additionally, contrary to the advice given to typical children, children with cystic fibrosis are told maintain a diet with a relatively high fat intake (Ramsey, Farrel, Pencharz, \& the Consensus Committee, 1992; Stark et al., 1995). Unfortunately, many children with cystic fibrosis do not follow a high calorie and high fat intake diet. On average, these children consume only $80 \%$ of the daily recommended allowance for healthy children (e.g., Hodges et al., 1984; Parson, Beaudry, Dumas, \& Pencharz, 1983). The resultant malnutrition has been found to be associated with both decreased lung functioning (Gurwitz, Corey, Francis, Crozier, \& Levison, 1979; Heijerman, 1993; Kraemer, Rudeberg, Hadorn, \& Rossi, 1978) as well as recovery from bacterial infection (Gurwitz et al.; Kramer et al.). Thus, increasing caloric intake with this population helps alleviate poor lung functioning, bacterial infections, and digestive inadequacies.

Improving the diet of children with cystic fibrosis is an important part of preventing lung disease; however, due to the high morbidity associated with pulmonary disease, more direct treatments of pulmonary dysfunction are warranted. Specifically, clearing the airways of the abnormal mucus and bacterial accumulation is essential to prevention of lung disease progression (e.g., Stark et al., 1995). One technique to remove excess mucus, chest physiotherapy (CPT), involves clapping on various locations of the patient's chest 1-4 times per day to loosen the mucus (Marshall et al., 2000; Stark et al., 1995). Patients can then expectorate the mucus. During this procedure, which is approximately 20-30 min long, the patient is required to move into certain positions to aid the drainage process (Stark, Miller, Plienes, \& Drabman, 1987). Inhalation therapy, a procedure that dilates the bronchioles in order to moisten and thin the mucus, is necessary to help some patients expel the mucus.

Exercise is another technique used to loosen excess mucus (Stark et al., 1995). Researchers tend to endorse that exercise aids sputum expectoration; however, there is some debate about the extent of exercise's benefits. For example, one study found that CPT was more effective at stimulating sputum expectoration than exercise (Salh, Bilton, Dodd, \& Webb, 1989). Additionally, the increase in sputum weight after exercise was not statistically significant. Like the study by Salh et al., a second examination of the benefits of exercise and CPT revealed that exercise was the least effective at clearing excess sputum when compared to CPT alone and CPT plus exercise (Bilton, Dodd, Abbot, \& Webb, 1992). These researchers recommend that exercise should be used as a supplement rather than a replacement for CPT. However, when looking at the literature as a whole, the previously mentioned studies represent the minority view. In fact, exercise has been shown to lead to greater sputum expectoration than that which occurs when the patient is resting, and the combination of exercise and CPT causes higher rate of expulsion than CPT alone (e.g., Baldwin, Hill, Peckham, \& Knox, 1994). A meta-analysis of the current literature echoes these findings (Thomas, Cook, \& Brooks, 1995). Moreover, many researchers advocate that exercise can replace CPT entirely (e.g., Blomquist, Freyschuss, Wiman, \& Strandvik, 1986). In one study, participants' CPT routine was discontinued while the participants completed a physical fitness training program (Stanghelle et al., 1988). Results not only demonstrated a significant increase in sputum expectoration, but also indicated that the children 
were highly motivated to exercise. A study by Zach, Oberwaldner, and Hausler (1982) reported similar results. When compared to the children's typical inhalation-physiotherapy routine, exercise was found to significantly increase sputum expectoration and improve airway functioning. In a long-term (30-month) study of the effects of a daily exercise program, CPT was discontinued after 12 months (Andreasson, Jonson, Kornfalt, Nordmark, \& Sandstrom, 1987). After CPT was halted, patients either maintained or improved their lung functioning. In fact, the authors stated that physical exercise should "be the basis of pulmonary therapy in cystic fibrosis" (p.70). Taken as a whole, these studies provide strong evidence that exercise can be used as an alternative or adjunct to CPT.

Obviously, increased sputum expectoration and airway functioning are highly important to this population; however, exercise has additional reported benefits. Specifically, studies of the effects of exercise on the health of individuals with cystic fibrosis have reported increased weight and exercise endurance (e.g., Alison et al., 1994; Cerny, Cropp, \& Bye, 1984; Heijerman, 1993; Homnick \& Marks, 1998). Also, exercise has been shown to lead to increased mobility, muscle strength, self-esteem, and well-being (Homnick \& Marks). More importantly, individuals with cystic fibrosis prefer exercise to other treatment options (Moorcroft, Dodd, \& Webb, 1998). Finally, exercise has been linked to improved disease status (Edlund et al., 1986).

Although exercise and other airway clearance techniques help with the immediate clearance of abnormal mucus in the lungs, they cannot prevent the re-accumulation of mucus. Thus, even patients that comply with their airway clearance treatment recommendations are highly susceptible to bacterial infection (Stark et al., 1995). Staphylococcus aureus and Pseudomonas aeruginosa are the two most common bacteria that cause infections (Marshall et al., 2000). Antibiotics are used to treat bacterial infections; however, Pseudomonas aeruginosa is unfortunately highly resistant to antibiotics, making treatment difficult. Due to the chronic secretions in the lungs, the patient can never be totally free of infection.

\section{Adherence to Treatment Recommendations}

The treatment regimen for cystic fibrosis is extensive and adherence to treatment recommendations is essential for longevity. Adherence has been most commonly defined as "the extent to which a person's behavior...coincides with medical or health advice” (Haynes, 1979, p. 2-3). Given the importance of treatment adherence, one might assume that adherence to treatment regimens would be high; however, non-adherence is rampant among pediatric populations. Researchers have stated that at least $50 \%$ of children suffering from medical conditions are non-adherent to their treatment regimen (La Greca \& Schuman, 1995; Litt, Cuskey, \& Rudd, 1980).

Several researchers have attempted to determine which variables are associated with nonadherent behavior (La Greca \& Schuman, 1995). One factor that has been related to regimen adherence is the disease itself. In general, individuals with chronic conditions are less likely to adhere to treatment recommendations than those with acute conditions (La Greca \& Shuman). Treatment complexity, which often accompanies chronic conditions, also has been associated with decreased adherence (e.g., Hudson, Fielding, Jones, \& McKendrick, 1987). Individuals with cystic fibrosis are faced with a chronic condition that requires an extremely complex treatment 
regimen. Not surprisingly, these factors hinder adherence (Quittner, Opipari, Regoli, Jacobsen, \& Eigen, 1992). Specifically, children with cystic fibrosis are required to take many medications; older children may take up to 80-100 pills each day (Gudas, Koocher, \& Wypij, 1991). Plus, patients with cystic fibrosis are told to eat large quantities of high calorie food for three full meals and several snacks each day (Stark, Bowen, Tyc, Evans, \& Passero, 1990). Finally, it is recommended that chest physiotherapy be completed up to four times per day, with each session lasting 20-30 min and sometimes requiring aerosol inhalation therapy to loosen and thin the mucus (Stark et al., 1987). Regular exercise is also an important treatment component (e.g., Andreasson et al., 1987). Past research has demonstrated that patients with cystic fibrosis report that their treatment regimen is too difficult to maintain (e.g., Fong, Dales, \& Tierney, 1990).

The immediacy of the benefits gained from adhering to treatment recommendations is also important to consider. Research has demonstrated that immediate reinforcement typically generates a higher response rate than delayed reinforcement (e.g., Doughty \& Lattal, 2003; Skinner, 1936; Sutphin, Byrne, \& Poling, 1998). When the benefits of adherence are easily and quickly observed, for example, when symptoms cease after taking antibiotics, patients are more likely to adhere (Arnhold et al., 1970; Gordis, Markowitz, \& Lilienfeld, 1969). However, it is often difficult for children to understand the necessity of adherence to treatment elements (e.g., consuming necessary vitamins) that produce no immediate effects but are necessary for positive long-term outcomes (Litt et al., 1980). In fact, because the initial symptoms of cystic fibrosis are often fairly mild, children and adolescents can experience a "honey moon" phase when they feel relatively good and may not appreciate the delayed benefits (e.g., increased lung strength) of lung clearance techniques (K. Moffett, personal communication, April 23, 2002). Adherence also is decreased when treatments have negative side effects (e.g., nausea, discomfort), even when non-adherence is life threatening, such as chemotherapy for pediatric cancer patients (Smith, Rosen, Trueworthy, \& Lowman, 1979).

Another variable associated with non-adherence is the developmental level of the child (La Greca \& Schuman, 1995). In general, young children are dependent on their caregivers to administer treatment regimen components; thus, parents' understanding of the disease and treatment and their coping and problem-solving skills are important to consider (Alexander, 1983; Fehrenbach \& Peterson, 1989). Not surprisingly, as with other chronic conditions, young children with cystic fibrosis depend on their caregivers for the administration of their treatment regimen. Although adolescents tend to be more knowledgeable about their disease and treatment than their younger counterparts, they typically are the least adherent age group (e.g., Anderson, Auslander, Jung, Miller, \& Santiago, 1990). Research with individuals with cystic fibrosis has shown that age is negatively correlated with adherence to treatment recommendations (Gudas et al., 1991). Some researchers have suggested that non-adherence among adolescents may be explained by a desire to feel "normal" compared to their peers (Friedman \& Litt, 1987).

Other variables to consider are individual factors associated with the child including emotional maturity, cognitive functioning, and controllability of the progression of the disease (e.g., La Greca \& Schuman, 1995). Often, these variables interact with the family system and combined can play a significant role in treatment adherence. Moreover, the multiple scheduled treatments and unscheduled medical difficulties can be highly disruptive of family routines, causing stress for the family as a whole (Quittner et al., 1992). 
Finally, adherence is affected by the physician who makes the treatment recommendations (La Greca \& Schuman, 1995). Both the rapport between the patient and physician and the individual characteristics of the physician (e.g., warmth and empathy) have been found to be linked to patient adherence (Gudas et al., 1991; Ievers et al., 1999; Litt et al., 1980). Another important factor is the clarity and consistency of the physician's recommendation (Freund, Johnson, Silverstein, \& Thomas, 1991). For example, the physician's recommendation may be too broad or vague, such as "get regular exercise." A more specific and easier to adhere to recommendation might be "perform aerobic exercise for $30 \mathrm{~min} 4$ times per week." In a recent study by Ievers et al. (1999), the relation between knowledge of, and adherence to, prescribed treatment recommendations was examined. The physician's recommended frequency and duration of airway clearance techniques, frequency of aerosol medications, and frequency of taking pancreatic enzymes was compared to parent and child knowledge of these recommendations. Results demonstrated that the parents and children's recollections of the treatment recommendations were vastly different from the physician's actual recommendations. Specifically, $12 \%$ to $32 \%$ of mothers could not accurately describe their child's treatment regimen and only half of the children could describe their own treatment. Other research has yielded similar results (Gudas et al., 1991). In this study, $40 \%$ of children and $47 \%$ of parents disagreed with their physician that a specialized diet had been recommended. Moreover, $12 \%$ of children and $9 \%$ of parents disagreed with their physician about whether CPT had been prescribed. Obviously, if the parents and children do not understand the treatment recommendations, they will have a difficult time following them.

\section{Treatment Adherence for Patients with Cystic Fibrosis}

Individuals with cystic fibrosis are vulnerable to many threats to treatment adherence; however, research has shown that certain treatment components are more problematic than others. The majority of the studies conducted with this population have found that individuals with cystic fibrosis are usually compliant with taking prescribed medications (e.g., Fong et al., 1990; Gudas et al., 1991; Passero, Remor, \& Solomon, 1981). An early study of adherence to medications demonstrated that adherence was high (80\%) for patients with cystic fibrosis (Meyers, Dolan, \& Mueller, 1975). Unfortunately, patients are less likely to comply with CPT (e.g., Fong et al., Gudas et al.) and diet (e.g., Gudas et al.) recommendations. To illustrate, Fong et al. revealed that only $9 \%$ of patients missed $25 \%$ or more of their prescribed medications. Unfortunately, this study also reported that $47 \%$ of patients missed $25 \%$ or more of their CPT sessions.

\section{Behavioral Techniques to Increase Regimen Adherence}

Even though it is somewhat reassuring that past research has indicated that patients with cystic fibrosis are typically adherent to taking their prescribed medications, the airway clearance and diet components of treatment are plagued by non-adherence. Considering that nutritional status affects pulmonary functioning (Gurwitz et al., 1979), and almost all studies indicate that pulmonary functioning is the main determinant of survival in this population (Walters, 2000), the lack of adherence to these treatment components is disheartening. In an attempt to address nonadherence, researchers have applied behavioral techniques to the diet and airway clearance treatment components (for a review, see Bernard \& Cohen, 2004). To date, most research has 
focused on the examination of the use of behavioral techniques to increase adherence to dietary recommendations.

Adherence to diet. Several studies by Stark and colleagues have examined the effects of behavioral techniques on dietary adherence for children with cystic fibrosis. The first of these studies employed behavioral techniques to increase adherence to dietary recommendations for five children (ages 5 to 12 years old) with cystic fibrosis (Stark et al, 1990). Parents attended six 90-min weekly group sessions during which they were educated about the following topics: nutritional education, behavior modification skills (e.g., praise, ignoring, contingency management), and implementation of a token economy. Children attended similar groups taught at an age appropriate level. On average, the children in this study increased their caloric consumption by 1,050 calories per day and these gains were maintained at a 9-month follow-up. Moreover, the children's height and weight increased; however, no changes were found in pulmonary functioning. Overall, the authors concluded that their behavioral intervention had successfully increased adherence to the diet treatment recommendations.

The previously discussed study was replicated with three mildly malnourished children with cystic fibrosis who ranged in age from 4 to 8 years old (Stark et al., 1993). Results echoed the prior study's findings and the children in this study increased their caloric intake by $46.9 \%$. A second replication of the study used a group design (Stark et al., 1996). In this study, five children in the treatment group were compared to four in the wait list control group. As predicted, the treatment group made significant gains in both caloric consumption and weight gain over the wait list control group.

Based on the results of this series of studies and a collection of anecdotal parent-report data, Stark and colleagues (Stark, Powers, Jelalian, Rape, \& Miller, 1994) hypothesized that improvement in parent-child mealtime interaction through nutritional education and parent training in behavioral techniques were primarily responsible for the intervention's success. In an attempt to tease apart the effects of nutritional education and behavioral techniques, the authors examined the use of behavioral techniques only in the modification of negative parent-child mealtime interactions. Two children participated in the study and parents were taught the following behavioral techniques: differential attention (i.e., praising appropriate behavior, ignoring inappropriate behavior), contingency management (i.e., a token economy system), setting realistic goals for mealtime behavior, and introducing new or non-preferred foods. Results demonstrated that parents were able to use these behavioral techniques effectively and child disruptive behavior during meals decreased while appropriate behavior increased. Additionally, the children's weight and caloric intake increased.

Another group of researchers, Singer et al. (Singer, Nofer, Benson-Szekely, \& Brooks, 1991), also examined the use of behavioral techniques to decrease problematic behaviors during mealtimes. Reinforcers (e.g., access to toys, praise, preferred foods) after appropriate mealtime behavior and time-out (i.e., removal of toys and attention) after inappropriate behavior were used to modify the behavior of four children with cystic fibrosis (ages 10 to 40 months). Parents also were taught how to use shaping, positive reinforcement, and ignoring. Like the studies by Stark and colleagues, results of this study demonstrated an increase in daily caloric intake from $54 \%$ to $92 \%$ of the daily recommended allowance. 
The studies examining the use of behavioral techniques to increase adherence to dietary recommendations have demonstrated that several behavioral techniques (e.g., praise, ignoring, token economies, contingency management) are effective. In fact, even though each of these studies had small sample sizes, the study replications (Stark et al., 1993; 1996) increase the validity of the findings. Unfortunately, all of the studies utilized a treatment package made up of several different behavioral techniques, rendering the effectiveness of each technique alone unknown. Another potential problem is the use of groups. Recent studies have suggested that certain bacteria are highly contagious and easily spread among individuals with cystic fibrosis (e.g., Ensor, Humphreys, Peckham, Webster, \& Knox, 1996; Ledson, Gallagher, Corkill, Hart, \& Walshaw, 1998; Webb \& Govan, 1998). Thus, treatment that uses child groups might pose risks to the health of children with cystic fibrosis.

Adherence to airway clearance techniques. Although the use of behavioral techniques to increase dietary adherence have been successful, surprisingly little research has examined the use of behavioral techniques to increase adherence to airway clearance methods. A search of the literature revealed that only two studies have used behavioral techniques to increase adherence to the traditional airway clearance methods, respiratory treatment and CPT (Hagopian \& Thompson, 1999; Stark et al., 1987). The first of these studies was designed to increase the frequency of CPT treatments for an 11-year-old girl. Behavioral contracting was used to increase adherence to the CPT regimen, which included use of a bronchodilator, pulmonary drainage procedures, and administration of an antibiotic aerosol three times each day (Stark et al., 1987). After behavioral contracting was introduced, the number of CPT treatments completed increased from 1 to 3 per day and the authors determined that behavioral contracting was an effective way to increase adherence to CPT treatments.

A second and more recent study examined the use of behavioral techniques to increase adherence to respiratory treatments (two consecutive 20-s inhalation sessions from an aerosol inhaler three times per day) in an 8-year-old boy suffering from cystic fibrosis, mental retardation, and autism (Hagopian \& Thompson, 1999). A functional analysis revealed that nonadherent behaviors were maintained by attention and escape and shaping and contingent reinforcement were used to modify the negative behaviors. Adherence increased from 13.8 seconds of cooperation per 40 -s session to an average of $97.7 \%$ cooperation. The authors concluded that shaping and contingent reinforcement could be used to effectively increase adherence to respiratory treatments.

These two studies represent good starting points for the examination of effective treatment avenues. However, because each study had only one participant, a significant amount of research is necessary before definitive conclusions can be drawn. Plus, the multiple diagnoses in the Hagopian \& Thompson (1999) study compromise the generalizability of the results. Moreover, recent literature has illuminated the importance of focusing our attention on increasing exercise in children with cystic fibrosis. Specifically, research has demonstrated that exercise is a viable replacement for CPT, that exercise has health benefits beyond lung clearance (e.g., improvement in cardiovascular fitness), that children prefer exercise to other airway clearance methods, and that exercise increases the child's self-esteem and well-being. Given the positive effects that have been associated with exercise, a comprehensive examination of the use of behavioral techniques to increase exercise is warranted. Sadly, studies of this nature are scant 
in the cystic fibrosis literature. A thorough review of the literature revealed only two unpublished studies examining increasing exercise with children with cystic fibrosis (Hobbs, Strutton, \& Kramer, 1988; Tuzin, 1993).

Hobbs et al. (1988) evaluated the effects of a home-based versus a hospital-based exercise program on the pulmonary functioning of 16 children ( 8 per group) ranging from 6 to 17 years old. The home-based program consisted of four 30- to 45-min exercise sessions and the use of self-monitoring, exercising with a partner, and behavioral contracting. Although little information was provided concerning the hospital-based group, the authors stated that no behavioral techniques were taught and the exercise sessions were similar in duration and frequency as the home-based group. Parent-report of patient exercise and pre- and post-treatment performance on pulmonary functioning measures indicated that both programs positively effected pulmonary functioning. Maintenance of these gains was demonstrated at 3- to 4-month follow-ups. The authors concluded that home-based exercise program was a feasible way to delay pulmonary deterioration. Unfortunately, the authors did not report information about adherence to or the effectiveness of the behavior modification techniques used in their study. Thus, the contribution of these techniques, both individually and in combination, to the success of the treatment is unclear.

The second study was clearer about the effects of behavioral techniques on exercise regimen adherence (Tuzin, 1983). Three children (ages 10, 10, and 14 years old) participated in the study. A multiple baseline design was used to demonstrate functional control. Both subjective (family report of the child's amount of physical activity) and objective (electronic activity meter) measures of physical activity were used and a token economy was implemented to encourage children to monitor their activity level. The intervention phase of the study consisted of bi-weekly meetings for 6 weeks during which the following behavior management principles were explained to both parents and children: shaping, goal-setting, contingency management, praise, differential attention, environmental monitoring, and self-monitoring. The contingency management portion was faded out towards the end of treatment. Results, based on mean differences between baseline and post-treatment scores, indicated increased physical activity for all three participants. Specifically, the children increased their physical activity by $19.6 \%, 84 \%$, and $138 \%$. The child who demonstrated the least treatment gain did demonstrate a $39 \%$ increase in targeted after school physical activities. Results also indicated that two of the three children improved their cardiopulmonary functioning. Overall, the author concluded that a behaviorally and home-based, parent-managed contingency management system significantly increased the children's level of physical activity.

Although these studies suggest that behavioral techniques can effectively increase exercise, it is important to interpret these results cautiously. Both studies are unpublished and neither has been subjected to peer review. The study by Hobbs et al. (1988) is a poster presentation, which contains sparse information about the methodology of the study, and the study by Tuzin (1983) is an unpublished masters thesis. Additional research in this area is clearly warranted. 


\section{Increasing Exercise in Other Chronic Conditions}

Studies with other chronic illnesses have more thoroughly examined the use of behavioral techniques to increase exercise and can be used to gain further insights into their effectiveness. A fairly extensive literature has evaluated the use of behavioral techniques to increase adherence to exercise in adult populations. For example, behavioral techniques such as behavioral contracting, self-monitoring, and positive reinforcement have effectively increased exercise in patients with chronic pain (e.g., Geiger, Todd, Clark, Miller, \& Kori, 1992) and patients at risk for cardiovascular disease (e.g., Neale, Singleton, Dupuis, \& Hess, 1990; Oldridge, 1982; Oldridge \& Jones, 1983; Schultz, 1993; Singleton, Neale, Hess, \& Dupuis, 1987).

Less literature has focused on pediatric chronic conditions even though research has proven that many chronic conditions would benefit from consistent exercise (Lampman, 1997). In fact, relatively few studies have attempted to increase adherence to exercise recommendations. A review of the diabetes literature revealed only one study that included increasing exercise adherence (e.g., Schafer, Glasgow, \& McCaul, 1982). In this study, self-monitoring, goal setting, and behavioral contracting increased exercise adherence in three adolescents. In the hemophilia literature, behavioral shaping and a token economy were used to increase adherence to exercise in 10 children and adolescents (Greenan-Fowler, Powell, \& Varni, 1987). However, by far the most extensive evaluation of the use of behavioral techniques to increase exercise is with childhood obesity. Of note, although many studies in the obesity literature have examined the use of behavioral techniques to decrease weight through a comprehensive treatment program including improved diet and increased physical activity (e.g., Coates, Jeffery, Slinkard, Killen, Danaher, 1982; Epstein et al., 1985), these studies did not focus on exercise specifically, making it impossible to determine the effectiveness of behavioral techniques on increasing exercise. However, a handful of studies specifically have targeted the use of behavioral techniques to increase exercise. These studies have used a variety of behavioral techniques to increase exercise including fixed interval schedules of reinforcement (De Luca \& Holborn, 1985; Jason \& Brackshaw, 1999), token economies (Epstein, Koeske, Zidansek, \& Wing, 1983; Epstein, Wing, Koeske, Ossip, \& Beck, 1982), and multi-component behavioral treatments (Epstein et al., 1995; Johnson et al., 1997).

In the obesity literature, two studies have examined the effects of a fixed interval schedule of reinforcement on increasing exercise adherence in obese children. DeLuca and Holborn (1985) utilized this technique with two obese and two non-obese 11-year-old boys. The boys were able to earn points for set periods of riding on a stationary bicycle that they could later exchange for prizes. Comparison of pre- and post-treatment means revealed that both groups of boys increased the amount of time spent exercising, although the obese boys decreased their rate of pedaling. Plus, the rates of exercise returned to baseline levels after the reinforcement schedule was removed. Overall, it appears as if the obese boys quickly figured out that they were being rewarded for the quantity and not the quality of their exercise behavior. Moreover, they were not receiving the maximum benefits of exercise.

A study by Jason and Brackshaw (1999) resulted in more positive results. Here, the authors used a preferred activity (i.e., watching television) to increase the exercise behavior of an 11-year-old girl. Specifically, a device was attached to the television set that required a set period 
of exercise on a stationary bicycle to be performed before television viewing could occur. Results indicated that exercise increased while television viewing (originally a high rate behavior) decreased. By the end of the intervention, the participant exercised for approximately one hour per day and maintained her weight loss at a 72-day follow-up. Although it appears that this was an effective intervention, the authors did not report rate of pedaling. Thus, like DeLuca and Holborn (1985), Jason and Brackshaw were not able to examine whether exercise was performed adequately. Further, the authors reported maintenance of weight loss, but did not report whether the child continued exercising.

Other researches have opted to use a different manner of reinforcement to increase exercise behavior. Epstein and colleagues have conducted studies (e.g., Epstein, Koeske, Zidansek, \& Wing, 1983; Epstein, Wing, Koeske, Ossip, \& Beck, 1982) utilizing a point system to increase adherence to the exercise component of a comprehensive treatment package. In one study (Epstein et al., 1983), a token economy was used to promote regular physical activity in 85 female and 28 male obese preadolescents. Results indicated decreased weight and significant changes in heart rate, with "high [weight change] success children" demonstrating a larger decrease in maximum and recovery heart rate than "moderate success children." A similar pattern emerged between "moderate" and "low success children." Essentially, this study indicates that children who lost the most weight benefited the most from the treatment. Unfortunately, this study did not report data on adherence, but rather implied that adherence had occurred because of reported changes in physical fitness status. Thus, it is impossible to determine if less successful children did not respond as well to the behavioral techniques or if other variables were associated with success or failure.

A second study examined the effectiveness of an exercise point system for thirty-seven 8 to 12 year old children (Epstein et al., 1982). In this study, lifestyle exercise, where the child could choose from a variety of aerobic activities each day, was compared to programmed exercise, where the child could choose only one aerobic exercise and perform it daily, either with or without a diet component. Results revealed that fitness level improved for both types of exercise; however, only the lifestyle group was able to maintain their improved fitness level. Overall, this study found that only children who were given choices in their exercise behavior were able to maintain their fitness gains. Moreover, it points to the importance of considering individual differences when designing interventions.

Some researchers have chosen to use multiple behavioral techniques to increase adherence to exercise. For example, Epstein et al. (1995) used the following behavioral techniques to increase adherence to the exercise component of an obesity treatment plan for 61 obese children ( 8 to 12 years old): behavioral contracting, self-monitoring, stimulus control, and positive reinforcement. In this study, the children were divided into three groups: reinforcement for reducing sedentary activity, reinforcement for increasing physical activity, and combined. Results demonstrated increased fitness and decreased weight for all groups. However, at a 1-year follow-up, the sedentary group demonstrated the greatest decrease in percentage overweight and body fat. The authors postulated that the children in the group reinforced for reducing sedentary activities had replaced sedentary activities with high-intensity activities. Moreover, children in the group reported an increase in their liking of high-intensity activity when compared to the 
exercise alone group. However, it should be noted that direct measures of type and intensity level of activity were lacking in this study.

In a second multi-technique study, researchers stated that a cognitive behavioral framework combined with a lottery to increase motivation were utilized to increase adherence to exercise and diet components of the treatment package for 32 obese children (Johnson et al., 1997). Twenty-three females and 9 males (ages 8 to 17 years old), were divided into three groups: nutrition and eating-habit change followed by exercise, exercise followed by nutrition and eating-habit change, and an information control. The researchers collected adherence data through an objective measure (i.e., a test of physical fitness) and a subjective measure (i.e., selfreport of time spent exercising and type of physical activity). Although the authors of this study were primarily concerned with changes in diet, they did report limited information about exercise adherence. Results revealed that the exercise first group increased their time devoted to highlevel activities by $25 \%$ and decreased their time spent in low-level activities by $37 \%$. However, even the information only group demonstrated a decrease of $17 \%$ in low-level activities. No information about exercise behavior was reported for the exercise second group.

Taken as a whole, the obesity research has shed some light on treatment effectiveness. Specifically, token economies and multi-component behavioral treatments seem to be more effective at increasing exercise behavior than fixed interval schedules of reinforcement.

Additionally, preliminary evidence suggests that providing the child with choices about the type of exercise they wish to complete seems to be more effective than prescribing a specific exercise (Epstein et al., 1982).

\section{Statement of the Problem}

In general, research has indicated that behavioral techniques provide an effective and practical way to increase adherence to cystic fibrosis treatment regimens. Specifically, research with diet, respiratory treatment, and CPT aspects of the cystic fibrosis treatment regimen has indicated that token economies, contingency management, and behavior modification have effectively increased adherence with this population. Unfortunately, very little research has been conducted that evaluates the use of behavioral techniques to increase exercise. However, a review of other pediatric chronic conditions has revealed that token economies and multicomponent treatments are viable treatment options.

The purpose of the current study was to examine the effectiveness of a token economy on increasing exercise adherence in children with cystic fibrosis. A token economy was selected for several reasons. First, although it is highly likely that multi-component treatments would be effective, it is important to first determine the efficacy of the individual treatment components before combining them. This allows for the development of the most cost-effective and least complicated treatment. Second, token economies have been shown to be effective in increasing exercise in other chronic conditions (e.g., Epstein et al., 1982; 1983). Additionally, as past literature has suggested that children are more adherent to recommendations for increased exercise when they have a choice of which exercise to complete rather than being prescribed one type of exercise, children in this study will be able to choose from a variety of aerobic exercises. 
In addition, allowing the children a variety of exercise choices increases the external validity of the study.

Participants in the current study were told to complete aerobic exercise four times per week for $30 \mathrm{~min}$ ( $5 \mathrm{~min}$ of pre-exercise stretching, $20 \mathrm{~min}$ of aerobic activity, $5 \mathrm{~min}$ of postexercise stretching). Parents were trained in the implementation of a token economy system and children were able to earn both immediate, small rewards and delayed, larger rewards for aerobic exercise. Data was collected about the type, frequency, and duration of exercise throughout the study as well as whether the child received immediate and delayed rewards during the treatment phases. Although target heart rate often is used as a marker for the appropriate level of aerobic exercise, children with cystic fibrosis experience difficulties exercising. These children may experience tachycardia to compensate for their lungs' inability to inhale enough oxygen, making heart rate an inaccurate measure of level of aerobic exercise. Thus, other measures of exercise exertion are necessary. In this study, children were trained to use the OMNI Scale of Perceived Exertion to assess level of aerobic exercise. Information also was collected about the children's fitness level, pulmonary functioning, body mass index (BMI), body fat percentage, quality of life, and attitude toward exercise at pre- and post-treatment sessions.

Hypotheses. Consistent with past research with other pediatric populations (e.g., Epstein et al., 1982; 1983), it was predicted that the token economy would effectively increase the aerobic activity of the participants. Specifically, it was expected that quantity of aerobic exercise would be low during the baseline and reversal phases and would approximate the prescribed level of aerobic exercise during the two treatment phases.

The study was designed to monitor the children's health (i.e., pulmonary functioning, exercise endurance, body mass index, percent body fat). Due to the short duration of the study and based on prior research (e.g., Zach et al., 1982), it was not expected that the children's pulmonary functioning would significantly improve. Specifically, an examination of the effects of exercise on pulmonary functioning has revealed that pulmonary functioning either maintains (e.g., Bilton et al., 1992) or declines more slowly (e.g., Schneiderman-Walker et al., 2000) in individuals who participate in regular exercise. Thus, in the current study, it was expected that the children's pulmonary functioning would not significantly decrease. It is important to keep in mind that pulmonary functioning will decrease just before and during a bout of illness and may not always be an accurate representation of the child's typical pulmonary functioning. Similarly, although past research has indicated increases in fitness level after the completion of an exercise program (e.g., Cerny et al., 1984; Heijerman, 1993), because of the short duration of the study, it was expected that the children in the current study would demonstrate neutral or slightly positive changes in fitness level.

Consistent with past research (e.g., Alison et al., 1994), moderate gains may be made in weight, but it was not expected that the child's BMI and body fat percentage would significantly increase. However, it was predicted that the children's body mass index and body fat percentage would not decrease during the study and that these measures might possibly demonstrate some improvement (i.e., increase in the percentile when compared to typical same-aged peers). 
Finally, prior research has found improvements in self-esteem and well-being to be associated with regular exercise (Homnick \& Marks, 1998). In the current study, it was expected that the children's reported quality of life would improve. Similar to prior research (Stanghelle et al., 1988), as exercise became less challenging for the children, it was expected that their enjoyment of exercise would increase.

\section{Participants}

\section{Method}

Participants included 3 female, Caucasian, pediatric patients with cystic fibrosis who received services at the Cystic Fibrosis Center at West Virginia University Health Sciences Center. Given that the exercise program was designed for school age children, participants ranged in age from 8 to 12 years old. Specifically, two of the participants were 12 and one was 8 years old. The children's physician referred these patients based on the perceived need for an exercise program and non-responsiveness to standard encouragement to increase exercise. Specific inclusion criteria included the following: First, only children who reportedly performed aerobic exercise no more than two times per week for a maximum of 20 min each time were included in the study. Children's current exercise was evaluated by the researcher and the physical therapist for type of exercise activity and level of exertion to determine eligibility. Second, because the exercise program was designed to increase exercise outside of the school setting, only exercise sessions that occurred after school hours were counted. Third, the children's forced expiratory volume in 1 second $\left(\mathrm{FEV}_{1}\right)$ needed to fall in the mildly impaired range. Although there is some variability in the suggested range of mild lung functioning impairment (Sarinas et al, 1998; Stanbrook, Corey, \& Tullis, 2004), the physician at the Cystic Fibrosis Center recommended using $70 \%$ as a minimum value; thus, this was the value used in the current investigation. Past research has indicated that the majority of individuals with mild lung disease can exercise safely at the same intensity as their same aged peers; however, individuals with more severe lung disease often require supplemental oxygen during exercise (e.g., Webb, Dodd, \& Moorcraft, 1995). In order to avoid possible health complications induced by increased exercise, only children with mild lung disease were considered for participation.

Of note, 3 additional children, aside from the 3 participants in the study, met the inclusion criteria but did not participate in the study. One 11-year-old male's family declined participation due to the step-mother suffering from medical problems. A 9-year-old female did not come to her scheduled appointments at the West Virginia University Cystic Fibrosis Center. Finally, an 11-year-old female began the baseline phase of the study but her parents refused to complete the exercise diaries and the participant subsequently had to be dropped from the study.

\section{Design}

A single-subject, $\mathrm{ABAB}$ design was used in this study. This design was selected because it allows for more definitive conclusions to be drawn about the effectiveness of the treatment in changing the target behavior than other single-subject approaches (Kazdin, 1998). Additionally, a single-subject approach allows for more detailed information about individual characteristics of the participants; detail that often is lost in group designs. Finally, this design allows for flexibility in the treatment; thus, treatment can be tailored for each individual participant. 


\section{Measures}

Background Information Form (See Appendix A). The Background Information Form was completed by the parents of the children participating in the study. This measure gathered the following information: child gender, child age, child race, parent age, parent and spouse education level, parent and spouse occupation, family income, and who lives at home with the child.

Children's OMNI Scale of Perceived Exertion. The Children's OMNI Scale of Perceived Exertion is a self-report measure of how difficult the exercise activity is for the child (Robertson et al., 2000). This measure is a rating scale that ranges from 0 ("not tired at all") to 10 ("very, very tired"), which allows children to rate their level of exertion for a variety of exercise types and intensities (Robertson et al., 2000; Utter, Robertson, Nieman, \& Kang, 2002). This measure is practical in that it is easy for children to understand and quick to complete. Additionally, research has proven that it is a reliable and valid measure of aerobic activity and has been validated with children ranging from 8 to 12 years old (Robertson et al., 2000; 2002; Utter et al.). Moreover, the physical therapist at the West Virginia University Cystic Fibrosis Center recommended using the Children's OMNI Scale of Perceived Exertion.

In this study, the experimenter trained the child about how to properly use the Children's OMNI Scale of Perceived Exertion. To determine the exertion level for exercise sessions, children were evaluated by the physical therapist on a case-by-case basis and were instructed by the experimenter to exercise at a perceived exertion level deemed appropriate by the physical therapist.

Exercise diaries (See Appendices $B$ and $C$ ). Exercise diaries were used to keep track of minutes of exercise per day. To obtain data on child exercise from both the parent(s) and the child, each was given their own diary to complete. In the diaries, the child and parent(s) documented the number of minutes and type of aerobic exercise the child performed each day. Additionally, parents recorded what occurred immediately after the child exercised, daily pedometer readings, and amount of time the pedometer was worn. Children recorded exertion ratings on days when they engaged in aerobic exercise. Families were informed that aerobic exercise was defined as physical activity during which the child's rating on the Children's OMNI Scale of Perceived Exertion matched or exceeded the physical therapist's recommendation. Additionally, parents and children were instructed to complete these diaries independent of one another. Finally, during the treatment phases, the parents and children were asked to record the same information and also whether the child received a reward for exercising and what the reward was.

Physiological measure of exercise. A Sportline 350 pedometer ${ }^{\circledR}$ was used to monitor the child's aerobic activity. Because this study was designed to asses exercise during non-school hours, children were instructed to wear the pedometer from when they got home from school each day to when they went to sleep at night. On the weekends and during periods of time when school was not in session, the children were instructed to wear the pedometer from when they woke up in the morning to when they went to sleep at night. The pedometer measures and stores seven days of information about the activity level of the child and allowed for the experimenter 
to obtain the total weekly data directly from the device. It also allowed parents to obtain daily step count readings from the device. Parents were told to ensure that the child wore the pedometer at the appropriate times.

Fitness level. To gain information about the children's fitness level, a 3-min step test was used. This measure involves having the individual step up and down on a single step that is approximately $15 \mathrm{~cm}$ high for 3 min at a rate of 30 steps per minute (Balfour-Lynn, Prasad, Laverty, Whitehead, Dinwiddie, 1998). Measures of oxygen saturation, which ranges from 0 to $100 \%$, and heart rate are then used to assess fitness level. Past research has indicated that the step test is a reliable and valid measure of fitness level for children with cystic fibrosis (e.g., Pike, Prasad, \& Balfour-Lynn, 2001). Studies have found that the typical value for oxygen saturation for children with cystic fibrosis during the 3-min step test is $93(S D=6)$; typical heart rate is 152 $(S D=19)$ (e.g., Balfour-Lyn et al., 1998; Orenstein, Holt, Rebovich, Campbell, \& Nixon, 2002). This measure was taken by the physical therapist during the initial baseline session and again during a follow-up session at the end of the study.

Pulmonary functioning. To monitor the children's pulmonary functioning, the appropriate pulmonary functioning tests for each child were conducted by the nurse at the Cystic Fibrosis Center. The Koko Spirometer, a device into which the child blows air, was used to measure pulmonary functioning. The specific pulmonary measures used for this study were forced vital capacity $(\mathrm{FVC})$ and forced expiratory volume in one second $\left(\mathrm{FEV}_{1}\right)$. These measures were taken during the initial baseline session and again during a follow-up session at the end of the study. Values for $\mathrm{FVC}$ and $\mathrm{FEV}_{1}$ are based on a $0-100 \%$ range although it is possible for an individual to receive a value greater than $100 \%$ if they perform better than the predicted value for their age and height. The cut-off for the normal range is the $95^{\text {th }}$ percentile (Knudson, Lebowitz, Holberg, \& Burrows, 1983).

Body mass index and body fat percentage. In order to monitor the children's weight and body fat make-up, their body mass index (BMI) and skin fold measures were obtained at the Cystic Fibrosis Center during the initial baseline session and again during a follow-up session at the end of the study. Both times, this measurement was made by the appropriate facility staff, who were trained in accurate BMI and skin fold assessment. Specifically, the nurse assessed the children's BMI and the physical therapist performed the skin fold measurements. (For typical ranges of BMI and body fat percentage for children, please see Kuczmarski et al., 2000 and Moore et al., 2003 respectively.)

Quality of life. Information about the children's quality of life was obtained using the Pediatric Quality of Life Inventory Version ${ }^{\mathrm{TM}} 4.0$ (PedsQL $\left.^{\mathrm{TM}} 4.0\right)$. This 23-item measure is designed to gather health-related quality of life information in children and adolescents ranging from 2 to 18 years old (Varni, Seid, \& Kurtin, 2001). There are developmentally appropriate forms for children ages 2-4, 5-7, 8-12, and 13-18 years. Both child and parent-proxy versions of the measure are available. Four domains are assessed by the $\mathrm{PedsQL}^{\mathrm{TM}} 4.0$ including physical functioning, emotional functioning, social functioning, and school functioning. This measure yields a Total Score, a Physical Health score, an Emotional Functioning score, a Social Functioning score, a School Functioning score, and a Psychosocial Health score which is made up of the Emotional, Social, and School Functioning scales. This measure has proven to be both 
reliable and valid for use with pediatric patients with either acute or chronic conditions (e.g., Varni et al., 2001) and has been found to be differentially sensitive to changes in disease severity (Varni, Seid, Knight, Uzark, \& Szer, 2002). For the purposes of this study, both the child and parent-proxy versions were completed prior to beginning and at the conclusion of the study.

Attitude towards exercise. To assess changes in the child's attitude toward exercise, children were asked to complete visual analog scales (VASs) to the following questions: "How much do you enjoy exercising?" "How difficult is exercise for you to do?" (see Appendix D). The VASs consisted of $100 \mathrm{~mm}$ horizontal lines with anchor phrases (e.g., Not at All, Very $M u c h$ ) on each end of the line. Children were asked to make a vertical mark along the VAS that corresponded to the point between the two anchors that indicated their response to the question. Past research with children with cystic fibrosis has demonstrated that VASs are reliable and valid with this population (e.g., Pike et al., 2001). This measure was completed at the initial session at the Cystic Fibrosis Center and at the end of each phase of the study.

\section{Procedure}

Baseline phase. The baseline phase of the study began with an initial visit to the Cystic Fibrosis Center. The researcher and physical therapist queried the parent and child about the child's current level of exercise including quantity of time spent exercising, type of exercise, and estimated exertion level. If participants met the inclusion criteria, the experimenter met with the child and his or her parent(s) for approximately one hour to explain the procedures of the study and obtain informed consent and child assent. This session began with brief definitions of the type of exercise targeted in this study (i.e., "aerobic exercise during which the child's rating on the Children's OMNI Scale of Perceived Exertion matches or exceeds the recommendation made by the physical therapist") and explanations about how to complete the exercise diaries and properly use the pedometer. Also, parents and children were provided a list of types of activities that qualified as aerobic exercise. This list was created on a case-by-case basis by the physical therapist at the Cystic Fibrosis Center and included age appropriate activities for each child. Examples of appropriate exercise activities included running/jogging, brisk walking, roller blading, swimming, soccer, and aerobics tapes. Activities that were included were sports that require continuous instead of intermittent movement (e.g., baseball, golf). Additionally, parents and children were informed that all families that completed the study would be entered in a drawing for a $\$ 100$ cash prize.

After the type of exercise included in this study was explained, the researcher administered the Background Information Form, PedsQL ${ }^{\mathrm{TM}}$ 4.0, and the VASs. Then, the participant's pulmonary functioning and body mass index were obtained by the nurse and the participant's fitness level and skin fold measures were assessed by the physical therapist. At this time, the physical therapist determined the appropriate exertion rating for exercise sessions for each child and the researcher subsequently explained to the child how to use the Children's OMNI Scale of Perceived Exertion.

During baseline, the parent(s) and child independently completed daily exercise diaries. The experimenter collected this self-report data from the parent(s) and child via phones calls made three times (approximately every other day) each week. Specifically, the child and 
parent(s) were asked how many minutes the child engaged in aerobic exercise daily since the last phone call. They also were asked the type of aerobic activity completed. Finally, parents were asked to provide daily pedometer readings. Because the study was designed to increase exercise above and beyond the level of exercise the child was currently doing, only exercise completed after the child had finished school for the day and on the weekends was monitored.

Treatment phase. Treatment consisted of two parts - training and implementation. During training, the experimenter went to the child's home for three 2-hr sessions. The first hour of the first session consisted of training the parent(s) to set up a token economy to reinforce the child's exercise behavior. Both the child and parent(s) participated in the session. The token economy was designed so that the child earned a small, immediate reward (which had been chosen by the child and approved by the parent(s) and experimenter) each time the child exercised. Specifically, after completion of an exercise session, children pulled one prize out of a grab bag that contained approximately 10 different types of rewards. The grab bag was used to help build anticipation and make the prize more rewarding. The child also was able to earn points each time she exercised that could be exchanged for prizes that the child had selected and the parent(s) and experimenter had approved. The list of prizes generated by the child, parent(s), and experimenter consisted of concrete items that were well defined and difficult for the child to satiate on (e.g., staying up for 30 min past their bedtime, playing their favorite game with their parent(s) for 20 min, going to see one movie that the child chooses).

During the second hour, the experimenter met with the child to teach her how to properly exercise to ensure that she was exercising at the appropriate level. This was done in a standardized fashion across subjects. Specifically, the experimenter trained the children how to properly stretch their muscles before beginning any type of exercise. The protocol used for the stretches was the same protocol used by the physical therapist at the Cystic Fibrosis Center and included stretches of the major leg muscle groups as well as the shoulders and upper back. Each child was provided an age-appropriate aerobic exercise tape with a 20-min aerobic exercise program on it. The aerobic video that was used in this study was the TAEBO® Junior (Volume 1), which consists of warm-up stretches, a 20-min aerobic workout (cardio kickboxing), and a 5min cool down period. The experimenter helped the child learn to perform the aerobic exercises on the TAEBO ${ }^{\circledR}$ Junior (Volume 1) tape correctly in order to reach the appropriate exercise level. The Children's OMNI Scale of Perceived Exertion was used to measure the child's exercise level.

After the child completed the exercises, the experimenter helped the parent(s) use the token economy reinforcement system. Finally, it was explained to the parent(s) and the child that during the study, the child could choose to use the exercise tape or any other activities on the previously mentioned list of appropriate exercises as long as the child exercised 4 times per week for at least 30-min sessions (5 min of pre-aerobic exercise stretching, 20 min of aerobic exercise, and 5 min of post-aerobic exercise stretching). The child and the parent(s) also were told that the child should exercise every other day (approximately three days during the week and one day on the weekend).

During the second 2-hr session, the experimenter conducted a brief psychoeducational session with the parent(s) and child. This session lasted approximately one hour and the 
experimenter provided information about proper diet for children with cystic fibrosis. Because an increase in exercise causes increased calorie expenditure, the underlying purpose of this session was to ensure that the parent(s) and child were aware of the proper diet to maintain given the increased calorie expenditure. The contents of this brief psychoeducational session were provided by a nutritionist at the Cystic Fibrosis Center. (See Appendix E for an outline of the material covered during this session.)

During the second hour, the experimenter met with the child to again practice the exercise routine on the exercise tape. The child exercised for $20 \mathrm{~min}$ at a rating that matched or exceeded the recommendation of the physical therapist. Finally, the experimenter observed the parent(s) implementing the token economy and corrected any errors.

During the third 2-hr session, the experimenter met with the parent(s) and child for approximately one hour to discuss any problems encountered with the token economy and problem solve with the family about how to rectify them. A pamphlet (see Appendix F for a list of topics contained in the pamphlet) created by the experimenter was provided to the parent(s) about common problems encountered with token economies (e.g., the child no longer seems motivated by the originally selected prizes, how to use the system during a family vacation).

During the second hour, the experimenter met with the child and observed her perform an exercise that the child chose off of the list of approved aerobic exercises. This provided some evidence that the child could generalize the correct level of exercise across types of exercise. It also provided some flexibility to the child in selecting an exercise the child enjoyed and might be more likely to do consistently, which adds to the external validity of the study. The experimenter ensured that the child was exercising at the appropriate level by monitoring their exercise via the Children's OMNI Scale of Perceived Exertion.

The next section of the treatment phase was designed to determine whether the token economy system effectively increased the child's quantity of aerobic exercise. Additionally, it provided some evidence of the ability of the parent(s) and child to use the token economy system. During this part of the treatment phase, the experimenter called the parent(s) three times per week and asked the following questions: "How many times has your child engaged in aerobic exercise since the last time I called?" "What aerobic activity did she perform?" "How many minutes did she exercise each time?" "Did the child receive her small reward soon after each exercise session?" "Has the child turned in any of her points for a larger prize?" "What are the daily step count readings from the pedometer?" and "How long did your child wear the pedometer?" The child was asked: "How many times have you exercised since the last time I talked with you?" "What activity did you choose to do?" "How many minutes did you exercise for each time?" "Did you receive your small reward after each session of exercise?" and "Have you turned in your exercise points for any prizes?"

Token economy (See Appendix $G$ ). A token economy was used to reinforce the children for regular exercise. The target aerobic exercise amount was approximately 4 times per week for $20 \mathrm{~min}$. The child earned an exercise point for each 10-min bout of aerobic exercise (stretching did not count towards earning points). However, the child also could earn bonus points for extra 10 -min exercise sessions up to a maximum of 40 extra minutes per week, with a maximum of 1 
bonus exercise point (a total of 30 min of aerobic exercise) per day. The child received a small reward (that cost no points) for each exercise session. The child could use the exercise points that she earned to receive larger prizes. The lowest prize level was set at 4 points, the equivalent of half of the target exercise quota for the week. Larger prizes were offered for 8 points, the equivalent of one week of exercising at the target level. The child also had the option to save and pool her points to cash in for larger prizes.

Reversal. During this phase the experimenter went to the participants' homes and removed the token economy and the pamphlet about problems associated with the token economies. A rationale for the return to baseline was provided. Specifically, parents were told that it is important to see if the treatment (token economy) was necessary for the child to continue exercising. The parent(s) were instructed to return to their typical behavior before the token economy was introduced. Additionally, they were asked not to provide rewards immediately after exercise or to provide larger rewards for their child contingent upon exercise. Children also were informed that prizes would no longer be given immediately after exercise and that although they were permitted to spend any points they already earned, they were not able to earn additional points during this part of the study.

During the reversal phase, the experimenter called the parent(s) three times per week and asked the following questions: "How many times has your child engaged in aerobic exercise since the last time I called?" "What aerobic activity did she perform?" "How many minutes did she exercise each time?" "What are the daily step count readings from the pedometer?" and "How long did your child wear the pedometer?" The child was asked: "How many times have you exercised since the last time I talked with you?" "What activity did you choose to do?" and "How many minutes did you exercise for each time?"

At the end of the phase, the experimenter asked the parents, "During the past two weeks, did you ever inadvertently reward your child for exercise?" Children were asked, "During the past two weeks, did your parents give you any rewards for exercise?" The purpose of these questions was to assess treatment integrity during this phase.

Return to treatment. During this phase the token economy materials previously removed from the families were returned and the parent(s) were instructed to begin using the system again. If the parent(s) or children inquired about problems encountered with the token economy during the tri-weekly experimenter phone calls, they were encouraged to do their best on their own and that the experimenter was not permitted to provide assistance. The rationale for this was to encourage self-sufficiency with the program in the hopes that it would lead to better long-term success.

At the end of this phase, children returned to the Cystic Fibrosis Center. At this time, the child's fitness level, pulmonary functioning, BMI, and skin fold measures were measured by the appropriate staff. Additionally, the researcher administered the PedsQL ${ }^{\mathrm{TM}} 4.0$ and VASs. After the surveys were administered, parents were offered the opportunity to have the experimenter come to their home for a "booster" token economy session(s). 
Results

\section{Integrity Checks}

Amount of exercise. The daily pedometer readings collected by the children's parents served as an integrity check in regards to the amount of reported aerobic exercise. These readings provided a gross estimate of overall level of activity. Of note, several problems were associated with the pedometer including parents forgetting to write down the reading, children forgetting to wear the pedometer (either for the day or while they were exercising), and the pedometer breaking (broken pedometers were replaced with new pedometers within two days of the experimenter learning of the broken device). However, for all three participants, the majority $(73 \%)$ of the daily readings across phases were recorded. The only exception was the return to treatment phase for Participant 3. Although pedometer readings were collected during this phase, they were inaccurate because out of the 13 days exercised during the 18 days of the phase, the child chose to swim for 3 days, ride her bike for 2 days, and both swim and ride her bike for 5 days. So, for 10 out of 13 days she exercised, this participant performed an exercise (i.e., swimming, biking) that the pedometer was not designed to record. Thus, the pedometer readings for the return to treatment phase for Participant 3 were not used.

In order to compare the pedometer readings across phases, the daily pedometer readings were converted into miles/hour by dividing the pedometer reading by the number of hours the child wore the pedometer that day. Then, to compare across phases, the daily miles/hour readings were summed and divided by the number of days in the phase. Thus, the average daily miles/hour was calculated for each phase and compared. It should be noted that it was not expected that there should be a large difference between the baseline and treatment phases. Because the children were asked to exercise every other day for 20 minutes, if they were adherent to this recommendation, there should be only a slight increase in their treatment pedometer readings over baseline. For example, if during baseline the child wore the pedometer for 6 hours each day, she would have a certain reading based on the walking she did during normal day-to-day activities. Then, during treatment, she would have an increase in activity for 20 minutes out of the 6 hours. Overall, this would only increase the treatment pedometer readings slightly over the baseline pedometer readings.

Pedometer data for Participant 1 was available for 14 out of 18 days $(78 \%)$ for the baseline condition, 13 out of 20 days (65\%) for the treatment condition, 17 out of 28 days $(61 \%)$ for the reversal condition, and 16 out of $18(89 \%)$ days for the return to treatment condition. The average daily miles per hour for Participant 1 were as follows: $0.09 \mathrm{miles} / \mathrm{hr}$ for the baseline phase, $0.31 \mathrm{miles} / \mathrm{hr}$ for the treatment phase, $0.19 \mathrm{miles} / \mathrm{hr}$ for the reversal phase, and 0.18 miles/hr for the return to treatment phase. Please note that during the reversal phase there was one data point that was an outlier, when the child was taken on a 2-hour hike by her friend's family. The participant's mother reported that it was extremely unusual for the participant to exercise for that long of a time and the data collected across all phases also indicates that this 2hour hike was highly unusual. With this data point removed, the average daily miles/hour was 0.15 for the reversal phase. It also is important to note that during the return to treatment phase, the child chose to ride her bike as her aerobic exercise for 4 out of the 18 days. Because the pedometer is not designed to record this type of aerobic activity, the daily pedometer readings on 
those days were lower than expected. When these days are removed from the average daily miles/hour, the phase average increases to 0.20 . If the two treatment phases are combined and compared to the two baseline phases by taking the difference and dividing by the baseline average, the average pedometer reading for Participant 1 increased $120.37 \%$ over baseline. Overall, the pedometer data indicates that the participant was exercising more during the treatment phases than during the baseline phases.

Similar to Participant 1, Participant 2 demonstrated higher average daily pedometer readings during the treatment phases than the baseline phases. Pedometer data was available for this participant for 12 out of 12 days (100\%) during the baseline condition, 22 out of 22 days $(100 \%)$ during the treatment condition, 9 out of 10 days $(90 \%)$ during the reversal phase, and 16 out of 20 days $(80 \%)$ during the return to treatment phase. However, for this participant, the parent had the child record the pedometer readings and hours the pedometer was worn despite several requests by the experimenter for the parent to record this information or at least supervise the child recording the information. The child was able to accurately record the pedometer readings (see Accuracy of pedometer readings section below); however, she appeared to have some difficulty correctly recording the number of hours the pedometer was worn. For example, the participant might report wearing the pedometer for 8 hours after attending school, but given the time the participant returned home after school and the child's typical bedtime, it would be highly unlikely that she wore the pedometer for that length of time. Thus, for this participant, the pedometer data might be less accurate than for the other two participants. The average daily miles per hour for Participant 2 were as follows: $0.24 \mathrm{miles} / \mathrm{hr}$ for the baseline phase, 0.22 miles $/ \mathrm{hr}$ for the treatment phase, $0.22 \mathrm{miles} / \mathrm{hr}$ for the reversal phase, and $0.36 \mathrm{miles} / \mathrm{hr}$ for the return to treatment phase. When the two treatment phases are combined and compared to the two baseline phases, the average pedometer reading for Participant 2 increased $26.05 \%$ over baseline.

Participant 3 also demonstrated a higher average daily pedometer reading during the treatment phases than the baseline phases. Pedometer data was available for this participant for 15 out of 26 days ( $58 \%$ ) during the baseline condition, 20 out of 32 days (63\%) during the treatment condition, and 4 out of 6 days (67\%) during the reversal phase. As previously discussed, the pedometer readings for the return to treatment phase were determined to be an inaccurate measure of the child's physical activity level and were not used. The average daily miles per hour for Participant 3 were as follows: $0.32 \mathrm{miles} / \mathrm{hr}$ for the baseline phase, 0.33 miles/hr for the treatment phase, and $0.22 \mathrm{miles} / \mathrm{hr}$ for the reversal phase. When the treatment phase is compared to the two baseline phases, the average pedometer reading for the treatment conditions for Participant 3 increased $21.25 \%$ over baseline.

Accuracy of pedometer readings. At the beginning and end of each phase of the study, the experimenter assessed the reliability of the parents' and child's reporting of the pedometer readings. Specifically, the Sportline 350 pedometer ${ }^{\circledR}$ has a feature which stores the pedometer readings for the prior seven days. The experimenter was able to access this information and compare it to the reported pedometer readings. For all three participants, the stored information matched the parent/child's report within 0.1 miles; this indicates that the parents/child were accurately reporting the pedometer readings. 
Treatment integrity. In order to ensure that parents were not purposefully or inadvertently rewarding their child for exercise during the reversal phase, this variable was briefly assessed at the end of the reversal phase. The parent and child were interviewed separately by the experimenter. For all three participants, parent and child verbally denied that the child received immediate or delayed rewards for exercise performed during the reversal phase.

\section{Treatment Effects}

The primary purpose of the intervention was to increase aerobic exercise. For each child, a graph was created that tracked the number of minutes the child exercised. Because the child was told to exercise every other day, data points were plotted that represent the number of minutes exercised across two days. Visual and numerical inspections of the graph were made to determine if there was a change in aerobic exercise behavior across phases (i.e., baseline, treatment, reversal, treatment). Figures 1, 2, and 3 show the amount of minutes exercised across phases. Of note, in order to change study phases, the data must have met one of the following criteria: 1) there were three or more stable data points, 2) there was a predictable pattern in the data, 3 ) there was no pattern per se, but the data points were predictably random.

Participant 1. Participant 1 was a 12-year-old, Caucasian female who lived with her biological mother, step-father, and two younger half-sisters, ages 4 and 6 . Prior to beginning the study, the participant's mother described the participant as a "couch potato" and reported that she did not exercise at all. The baseline phase was 18 days and the participant completed almost no exercise during this time. In fact, she exercised only one time for 10 minutes. During part one (the training part) of the treatment phase, the participant exercised at the appropriate level and she exercised relatively consistently during the second part of the treatment phase. Her number of minutes exercised dropped to zero on two occasions. First, just after the training part was completed, the patient became ill for a few days and did not exercise during that time. The second drop was due to the participant choosing not to exercise for two days. However, she then returned to exercising consistently at the prescribed level. During the reversal phase, she exercised more than she did in the baseline phase, but less than in the treatment phase. On one occasion, the patient went for a 2-hour hike with her friend's family, which accounts for the outlier data point. When the return to treatment phase was implemented, the participant's mother adjusted the prizes for the token economy. The participant's level of exercise was highest during this phase. (See Figure 1.)

Participant 2. Participant 2 also was a 12-year-old, Caucasian female. She lived with her adoptive parents and her four biological siblings: twin brother, older brother (age 13), older sister (age 15), and younger sister (age 9). Of the three participants, this participant's data were the most stable. She demonstrated very little exercise during the baseline phase, exercising only one time over a period of 12 days. During the training part of the treatment phase, she exercised above the expected level because she chose to do the TaeBo ${ }^{\circledR}$ work-out on non-training days as well as training days. She then consistently exercised for $2 \frac{1}{2}$ weeks at the prescribed level. During the reversal phase she returned to the amount of exercise she had completed during the baseline phase. Finally, in the return to treatment phase, the participant again began exercising at the prescribed amount. In fact, over a period of 20 days, she only missed one prescribed exercise session. (See Figure 2.) 


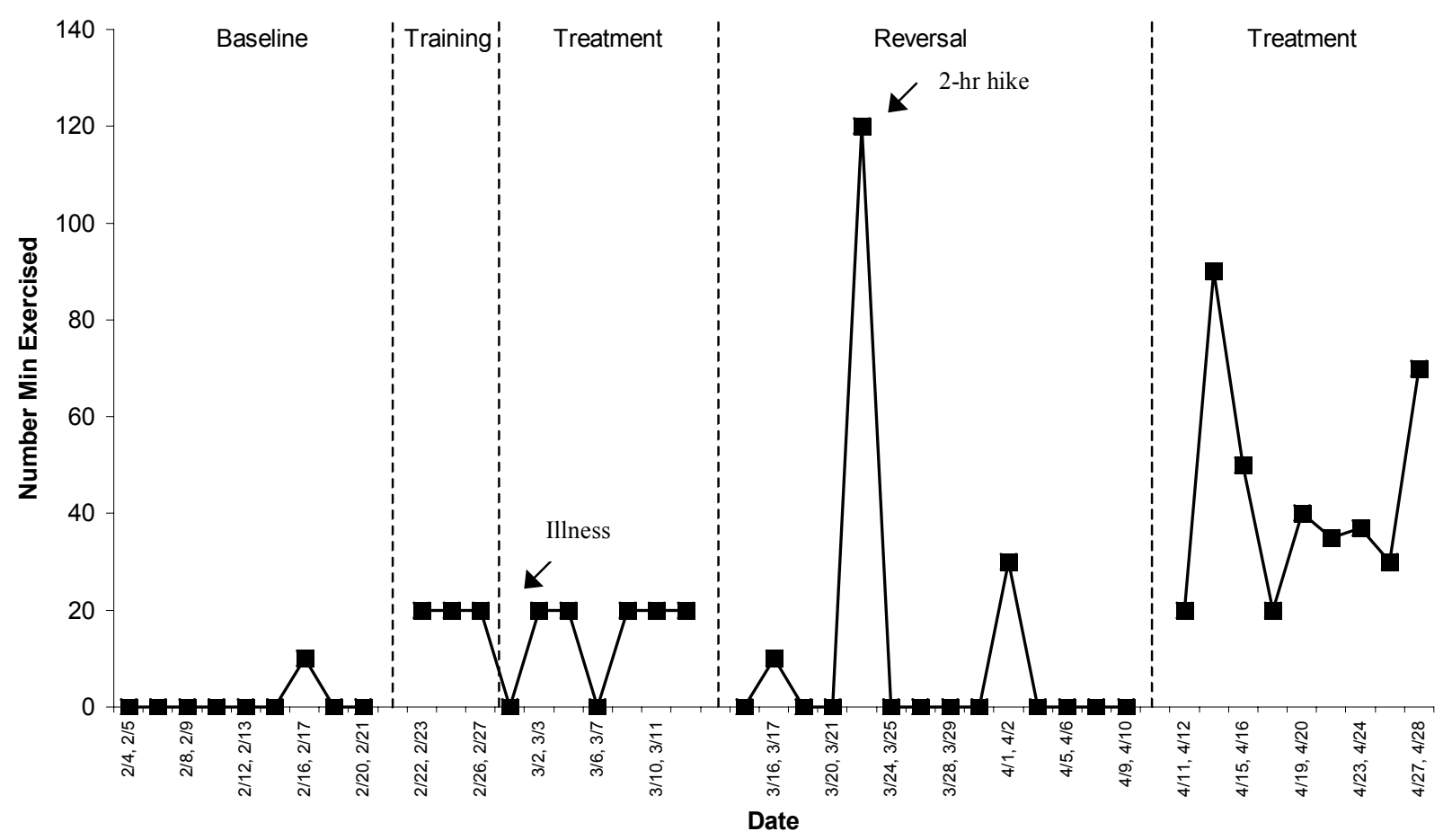

Figure 1. Results by phase of minutes exercised across days for Participant 1. Each data point on the graph represents the number of min exercised across two days.

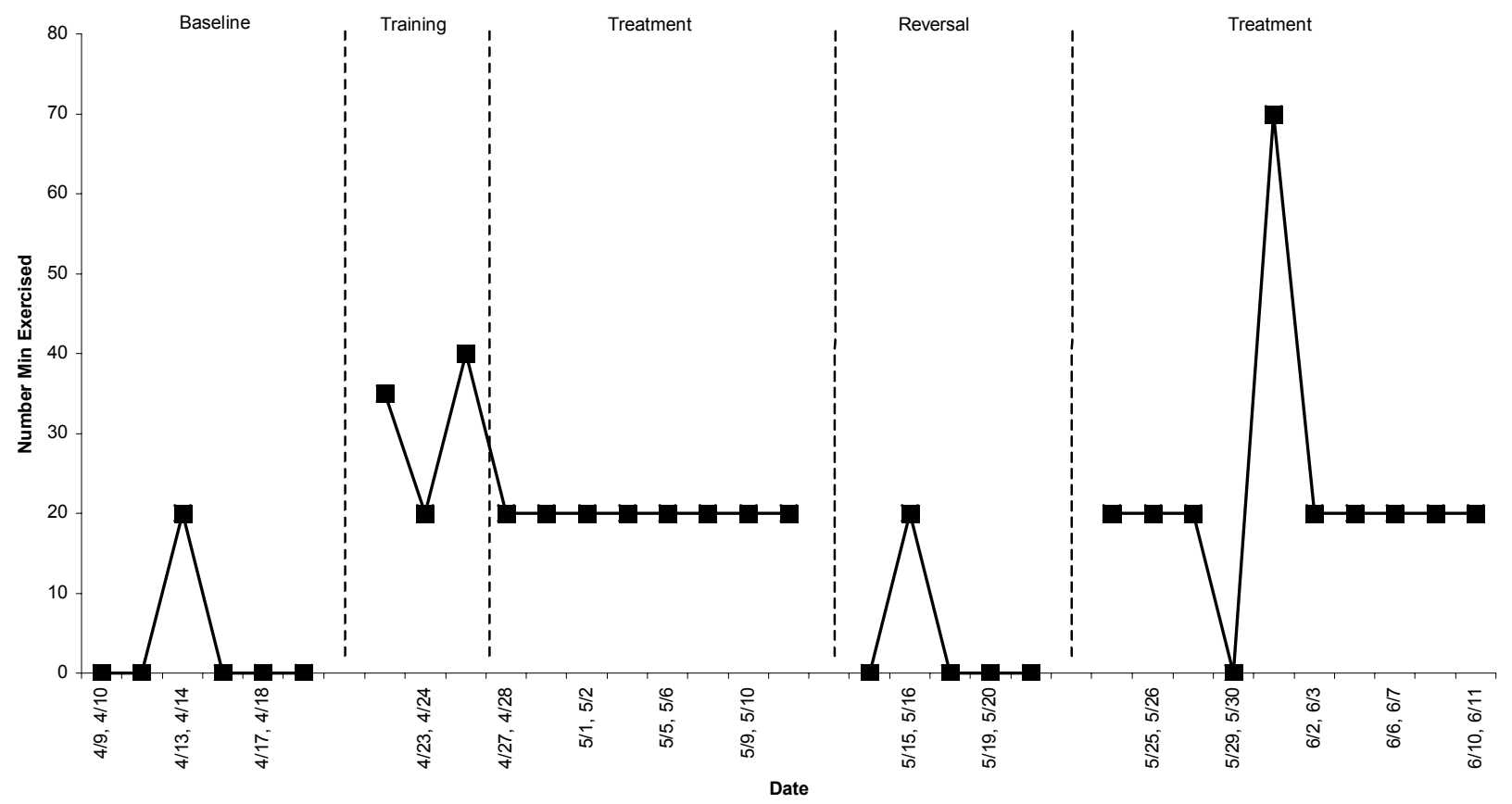

Figure 2. Results by phase of minutes exercised across days for Participant 2. Each data point on the graph represents the number of min exercised across two days. 
Participant 3. Participant 3 was an 8-year-old, Caucasian female who lived with her mother, father, and 5-year-old sister. At the initial session at the Cystic Fibrosis Center, the participant's mother reported that this participant was enrolled in a weekly dance class. During the study, the participant attended this weekly class throughout the baseline and treatment phases, but not during the reversal and return to treatment phases due to the class ending. The weekly exercise class accounts for the pattern seen in the data during the baseline phase, where she would exercise once per week. During the training part of the treatment phase, the participant exercised above the expected level because she had dance class on one of the non-training days. Compared to the baseline phase, the participant increased her frequency of exercise during the implementation part of the treatment phase. However, the amount of exercise completed varied. Some variation was expected due to the fact that the participant was enrolled in the weekly dance class. In other words, it was expected that there should be weekly spikes in the data. There were also two occasions over the 26-day period that the participant did not exercise at all. On one of these occasions, parent and child reported that the child was too ill to exercise. Overall, during the treatment phase, this participant increased her exercise over the baseline phase, but was not consistent in the amount of exercise she completed. Near the end of the treatment phase, the participant's dance class ended. During the reversal phase, the participant completed no exercise. In the return to treatment phase, the participant's exercise increased significantly. During the 18day period, the participant only missed one exercise session and primarily exercised well above the prescribed amount. Of note, the participant chose swimming as her primary exercise during this phase. (See Figure 3.)

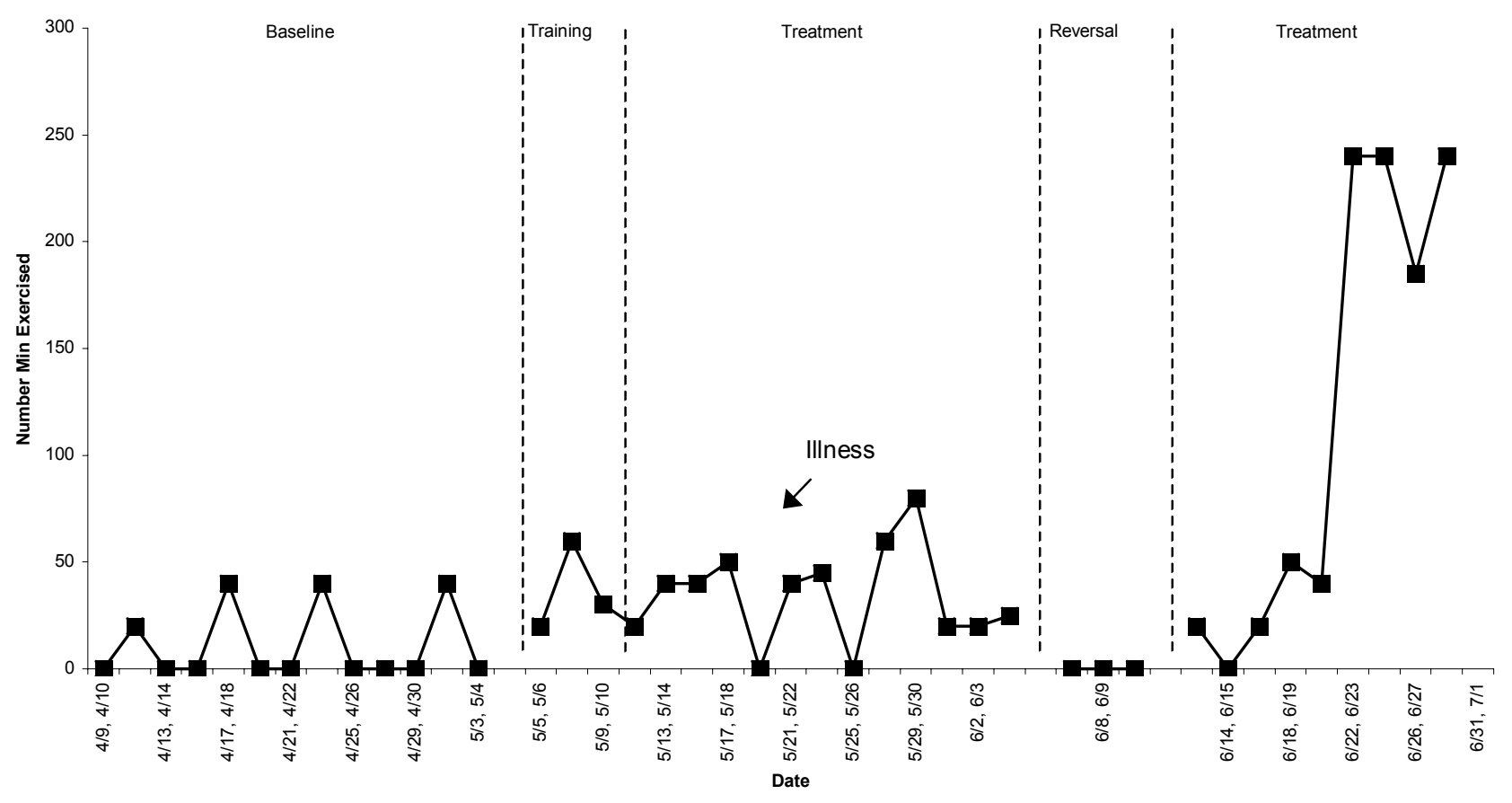

Figure 3. Results by phase of minutes exercised across days for Participant 3. Each data point on the graph represents the number of min exercised across two days. 
Percent change. Percent change from baseline to treatment was calculated for each participant. This was done by taking the average of the last 3-5 stable data points for each phase, finding the average of the stable data points for the combined baseline phases and the combined treatment phases, taking the difference between the baseline and treatment phases, and dividing by the average for the stable data points of the combined baseline phases. If the child exercised for an average of one minute or less, the calculation was completed assuming the baseline average was one minute. For Participant 1, the averages for each phase were: $3 \mathrm{~min} 20 \mathrm{~s}$ for the baseline phase, $20 \mathrm{~min}$ for the treatment phase, $0 \mathrm{~min}$ for the reversal phase, and $34 \mathrm{~min}$ for the return to treatment phase. The percent change from baseline to treatment was $1520.00 \%$, which represents a 15-fold increase. The average number of minutes exercised for Participant 2 were: 0 min for the baseline phase, $20 \mathrm{~min}$ for the treatment phase, 0 min for the reversal phase, and 20 min for the return to treatment phase. The percent change from baseline to treatment was $1900.00 \%$, which is a 19-fold increase. For participant 3, the averages for each phase were: 8 min during the baseline phase, $21 \mathrm{~min}$ and $40 \mathrm{~s}$ during the treatment phase, 0 min during the reversal phase, and $221 \mathrm{~min}$ and $40 \mathrm{~s}$ during the return to treatment phase. If the data are considered before the child began swimming, the average for the return to treatment phase was $36 \mathrm{~min}$ and $40 \mathrm{~s}$. Because this number was more representative of the child's exercise during the year (she can only swim during the summer months), it was used in the percent change calculation. The percent change from baseline to treatment was $629.17 \%$, which is a 6 -fold increase.

Average daily exercise. Additionally, an "average daily exercise" was calculated for the four phases by summing the total number of minutes exercised and dividing by the number of days in the phase. (Of note, the previously mentioned outlier for the reversal phase for Participant 1 was removed.) The four averages were then compared. Given that the recommended exercise regimen was 20 min of aerobic exercise every other day, if the child exercised at the prescribed level, the average daily exercise would be $10 \mathrm{~min}$. For Participant 1, the averages were: $33 \mathrm{~s}$ per day for the baseline phase, 8 min per day for the treatment phase, 1 $\min 32 \mathrm{~s}$ per day for the reversal phase, and $21 \mathrm{~min} 47 \mathrm{~s}$ per day for the return to treatment phase. During the baseline phases, this participant exercised well below the prescribed level. Her level of exercise during the first treatment phase was just below the expected level and increased to twice the prescribed level during the return to treatment phase. The average daily exercise for Participant 2 was: $1 \mathrm{~min} 40 \mathrm{~s}$ per day for the baseline phase, $11 \mathrm{~min} 35 \mathrm{~s}$ per day for the treatment phase, $2 \mathrm{~min}$ per day for the reversal phase, and $11 \mathrm{~min} 30 \mathrm{~s}$ per day for the return to treatment phase. This participant consistently exercised well below the recommended level during the baseline phases and at the prescribed level during the treatment phases. For Participant 3, the averages were: $5 \mathrm{~min} 23 \mathrm{~s}$ per day during the baseline phase, $17 \mathrm{~min} 11 \mathrm{~s}$ per day during the treatment phase, 0 min per day during the reversal phase, and $57 \mathrm{~min} 30 \mathrm{~s}$ per day during the return to treatment phase. If only the time prior to the child being able to swim is considered, the average daily exercise for the return to treatment phase would be 13 min. Because this child was enrolled in a weekly dance class, her level of exercise was higher than that of the other two participants, but she was still below the recommended level during the initial baseline condition. She did not exercise at all during the reversal phase. Her level of exercise increased to above the prescribed level for both of the treatment phases. 
Average days exercised per week. Finally, data was analyzed by calculating the mean number of days exercised per week for each phase of the study. A bar graph was created to demonstrate changes across phases (see Figure 4). Days when the child exercised were defined as days when the child exercised aerobically for at least $10 \mathrm{~min}$. If the child exercised at the prescribed level, every other day, the average days exercised per week would be 3.5 days. For Participant 1, the average days exercised per week increased from less than one day per week during baseline phases to the recommended level during the return to treatment phase.

Specifically, this participant exercised an average of 0.39 days during the baseline phase, 2.8 days during the treatment phase, 0.75 days during the reversal phase, and 4.28 days during the return to treatment phase. Participant 2 also increased from less than one day per week during the baseline phases to the prescribed exercise level during the treatment phases. Weekly averages for Participant 2 were: 0.58 days during the baseline phase, 4.14 days during the treatment phase, 0.70 days during the reversal phase, and 3.5 days during the return to treatment phase.

Participant 3 exercised an average of 1.08 days per week during the baseline phase, when she was enrolled in a weekly dance class, and 0 days per week during the reversal phase when she was no longer enrolled in the dance class. Her average weekly exercise increased to 3.94 days during the treatment phase and 5.06 days during the return to treatment phase.

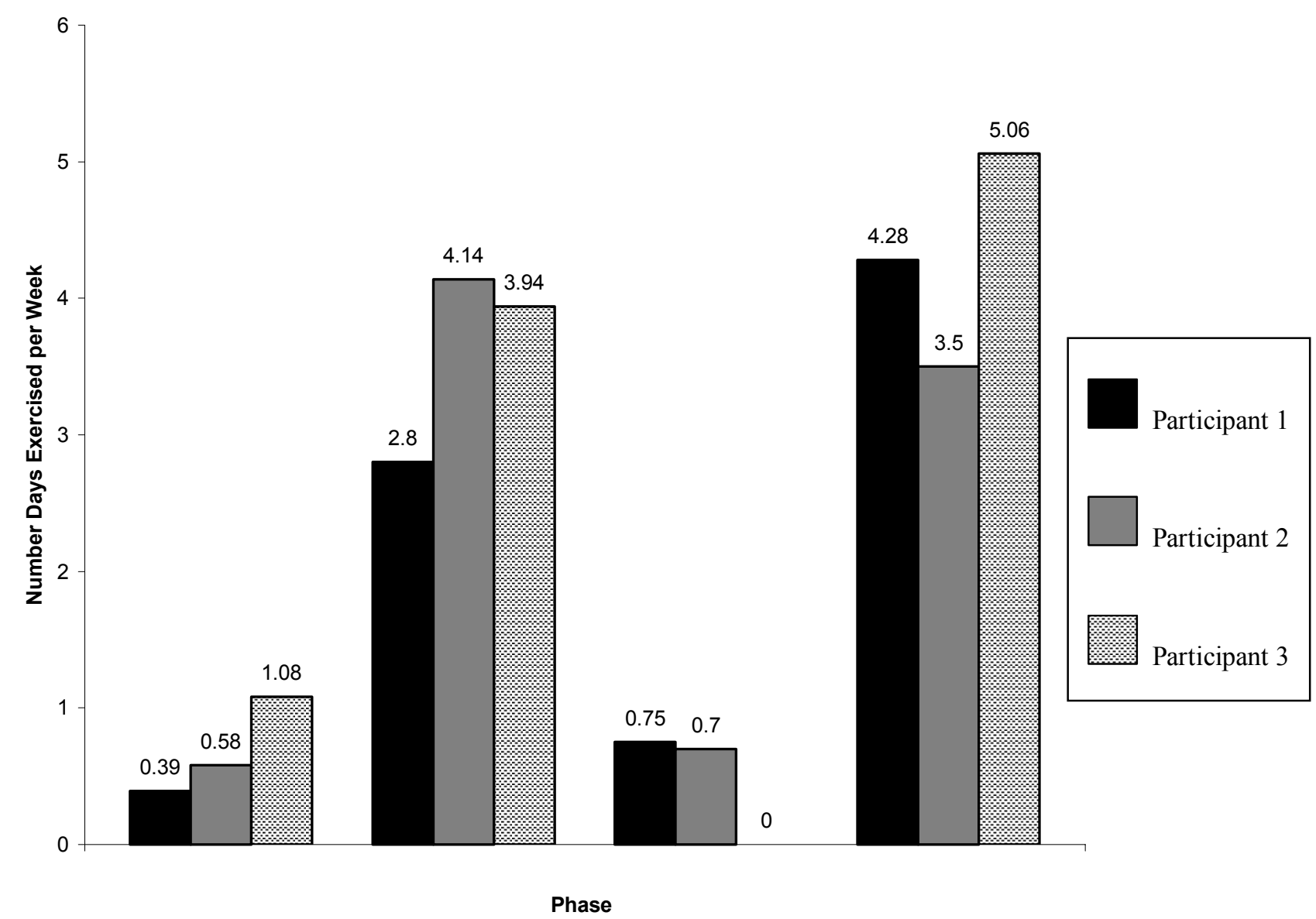

Figure 4. Average number of days exercised per week by phase for each participant. 


\section{Medical Monitoring}

For all three participants, physiological variables were assessed to monitor the children's health. Specifically, the following measures were taken at pre- and post-treatment: FEV 1, FVC, BMI, body fat percentage (skin folds of triceps and calf), oxygen saturation during 3-min step test, and heart rate after 3-min step test. Across participants, health measures remained relatively stable (see Table 1). More specifically, $\mathrm{FEV}_{1}$ and $\mathrm{FVC}$ remained within or above the mildly impaired range ( $\geq 60 \%$ ), for all three participants (for description of ranges, see Sarinas et al., 1998; Stettler et al., 2000). Additionally, body fat percentage and BMI did not change significantly; however, body fat percentage increased for all three participants and Participant 1's BMI increased whereas the other participants' BMI decreased slightly but remained within the expected range for children with cystic fibrosis (Lai, Corey, FitzSimmons, Kosorok, \& Farrell, 1999). Of note, because there is wide individual variation for the onset of puberty and growth rate during preadolescence, there can be considerable variability in BMI for this age range (Karlberg, Kwan, Gelander, \& Albertsson-Wikland, 2003), which may explain the slight decrease for two of the participants. Oxygen saturation and heart rate after the 3-min step test were within expected limits at post-treatment in respect to baseline measurements (Narang, Pike, Rosenthal, Balfour-Lynn, \& Bush, 2003).

Table 1

Medical Monitoring Measure Scores at Pre- and Post-Treatment

\begin{tabular}{|c|c|c|c|c|c|c|}
\hline \multirow[b]{2}{*}{ Monitoring Measure } & \multicolumn{2}{|c|}{ Participant 1} & \multicolumn{2}{|c|}{ Participant 2} & \multicolumn{2}{|c|}{ Participant 3} \\
\hline & Pre & Post & Pre & Post & Pre & Post \\
\hline $\mathrm{FEV}_{1}$ & $70 \%$ & $70 \%$ & $97 \%$ & $91 \%$ & $97 \%$ & $90 \%$ \\
\hline FVC & $81 \%$ & $86 \%$ & $100 \%$ & $93 \%$ & $103 \%$ & $96 \%$ \\
\hline BMI & 18.92 & 19.73 & 19.13 & 18.31 & 16.25 & 15.56 \\
\hline Body Fat Percentage & 25.23 & 27.06 & 20.35 & 25.23 & 20.96 & 23.40 \\
\hline $\mathrm{O}_{2}$ Saturation (step test) & $83 \%$ & $96 \%$ & $94 \%$ & $95 \%$ & $93 \%$ & $97 \%$ \\
\hline Heart Rate (step test) & 176 & 150 & 124 & 135 & 145 & 155 \\
\hline
\end{tabular}

Quality of Life

The PedsQL ${ }^{\mathrm{TM}} 4.0$ child self-report and parent-proxy versions were used to assess child quality of life and were given prior to baseline (pre) and at study completion (post) (see Table 2). Higher scores on this measure indicate perceptions of higher quality of life. For each child, the pre- and post-treatment scores on PedsQL ${ }^{\mathrm{TM}} 4.0$ were calculated and compared. Specifically, the 
change in score was examined for the Total Score for the measure as well as each of the scale's four dimensions (i.e., Physical Health, Emotional Functioning, Social Functioning, and School Functioning) and the Psychosocial Health scale which is made up of the Emotional, Social, and School scales. A recent study by Varni, Burwinkle, Seid, and Skarr (2004) demonstrated the reliability and validity of this measure for use with pediatric populations. In this study, 10,241 families completed the PedsQL ${ }^{\mathrm{TM}} 4.0$ and from these parent and child responses, population means as well as chronic condition means were created for the Total Score, Psychosocial Health scale, and each of the four dimensions. For children with chronic illnesses, the mean Total Score for child self-report is $74.16(S D=15.38)$ and the mean Total Score for parent proxy-report is 73.14. $(S D=16.46)$. Of note, for healthy children the mean Total Score for the child self-report is $83.91(S D=12.47)$ and the mean Total Score for parent proxy-report is $82.29(S D=15.55)$. One standard deviation below the population mean, which is 69.7 for the child self-report and 65.4 for the parent-proxy, can be used as a cut-off score for poor health related quality of life. These researchers also outlined minimal clinically important difference scores for the Total Score and each of the dimensions. For example, the minimal clinically significant difference for the Total Score is 4.36 .

Table 2

Mean Pre- and Post-Treatment Peds $Q L^{T M} 4.0$ Scores

\begin{tabular}{lllllll}
\hline & \multicolumn{2}{c}{ Participant 1 } & Participant 2 & Participant 3 \\
\cline { 2 - 6 } & & & & & \\
Scale & Pre & Post & Pre & Post & Pre & Post \\
\hline & & & & & & \\
Child Self-Report & & & & & & \\
Total Score & 70.65 & $81.25^{* *}$ & 91.30 & $98.91^{*}$ & 77.17 & $68.48^{\lambda}$ \\
$\quad$ Physical Health & 71.86 & $81.25^{*}$ & 93.75 & 96.88 & 87.50 & $68.75^{\lambda \lambda}$ \\
Psychosocial Health & 70.00 & $81.67^{* *}$ & 90.00 & $100.00^{*}$ & 71.67 & 68.33 \\
$\quad$ Emotional Functioning & 75.00 & 80.00 & 85.00 & $100.00^{*}$ & 75.00 & $60.00^{\lambda}$ \\
$\quad$ Social Functioning & 60.00 & $80.00^{* *}$ & 90.00 & $100.00^{*}$ & 80.00 & $70.00^{\lambda}$ \\
$\quad$ School Functioning & 75.00 & $85.00^{*}$ & 95.00 & 100.00 & 60.00 & $75.00^{*}$ \\
Parent Proxy-Report & & & & & & \\
Total Score & 53.26 & $67.39^{* * *}$ & 94.75 & 93.48 & 84.78 & 80.43 \\
$\quad$ Physical Health & 50.00 & $62.50^{*}$ & 100.00 & $90.63^{\lambda}$ & 81.25 & 81.25 \\
Psychosocial Health & 58.33 & $70.00^{* *}$ & 91.67 & 95.00 & 86.67 & $80.00^{\lambda}$ \\
Emotional Functioning & 55.00 & $70.00^{*}$ & 90.00 & $100.00^{*}$ & 75.00 & 75.00 \\
$\quad$ Social Functioning & 50.00 & $60.00^{*}$ & 100.00 & 100.00 & 90.00 & 85.00 \\
$\quad$ School Functioning & 70.00 & $80.00^{*}$ & 85.00 & 85.00 & 95.00 & $80.00^{\lambda}$ \\
& & & & & & \\
\hline
\end{tabular}

* Improvement by the minimal clinically important difference.

** Improvement by two times the minimal clinically important difference.

*** Improvement by three times the minimal clinically important difference.

$\lambda$ Decrease by the minimal clinically important difference.

${ }^{\lambda \lambda}$ Decrease by two times the minimal clinically important difference.

For Participant 1, both parent and child reported that the participant's quality of life improved from pre- to post-treatment. At baseline, the child reported scores on all scales (i.e., 
Total Score $=70.65$, Psychosocial Health $=70$, Emotional Functioning $=75$, School Functioning $=75)$ were within one standard deviation of the mean when compared to the norm group of children with chronic illnesses and only the Physical Health (71.86) and Social Functioning (60) scales were more than one standard deviation below the population mean. At post-treatment, she demonstrated clinically important improvement on all scales (Total Score $=81.25$, Physical Health $=81.25$, Psychosocial Health $=81.67$, Social Functioning $=80$, School Functioning $=85$ ) except for the Emotional Functioning scale (80), which improved slightly but not significantly. Parent-proxy report at baseline was lower overall than child self-report with the Total Score (53.26), Physical Health (50), and Social Functioning (50) scores falling more than one standard deviation below the means for chronic populations and all scales, except for the School Functioning scale (70; which was within normal limits), falling one standard deviation below the population means. At post-treatment, all scores for the parent proxy-report demonstrated clinically important improvement with all scales falling within normal limits when compared to the chronic illness population and only the Physical Health scale (62.5) and Social Functioning scale (60) falling one standard deviation below the population means.

Baseline child-report scores for Participant 2 were all above the means when compared to chronic illness and population norms (Total Score $=91.3$, Physical Health $=93.75$, Psychosocial Health $=90$, Emotional Functioning $=85$, Social Functioning $=90$, School Functioning $=95$ ) The Total Score, Psychosocial Health, and School Functioning scales fell one standard deviation above the chronic illness means. At post-treatment, the participant reported clinically important improvement for all scales except the Physical Health (96.88) and School Functioning (100) scales, which improved but not significantly. This placed all scales at one standard deviation above the chronic illness means and all scales except the Physical Health scale at one standard deviation above the population means. Parent proxy-report indicated that, at baseline, the child was above the chronic illness and population means for all scales (Total Score $=94.75$, Physical Health $=100$, Psychosocial Health $=91.67$, Emotional Functioning $=90$, Social Functioning $=$ 100, School Functioning = 85). Specifically, all scales except the Emotional Functioning and School Functioning scales fell one standard deviation above the chronic illness means and the Physical Health and Social Functioning scales fell one standard deviation above the population means. Post-treatment scores were mixed with the Physical Health score (90.63) decreasing at the clinically important level but still remaining above the population mean and the Emotional Functioning scale (100) demonstrating clinically important improvement, falling one standard deviation above the chronic illness and population means.

For Participant 3, at baseline all scales for child self-report were within normal limits when compared to the chronic illness means (Total Score $=77.17$, Physical Health $=87.5$, Psychosocial Health $=71.67$, Emotional Functioning $=75$, Social Functioning $=80$, School Functioning $=60$ ). Only the School Functioning scale fell one standard deviation below the population mean. At post-treatment, scores remained within normal limits when compared to the chronic illness means. The Total Score (68.48), Physical Health (68.75), Emotional Functioning (60), and Social Functioning (70) scales all decreased at the clinically important level and the Total Score and Physical Health scale fell one standard deviation below the population means. School Functioning (75) increased at the clinically important level. Parent proxy-report at baseline indicated that all scales were within normal limits when compared to the chronic illness and population mean scores with School Functioning falling one standard deviation above the 
mean for chronic illnesses $($ Total Score $=84.78$, Physical Health $=81.25$, Psychosocial Health $=$ 86.67, Emotional Functioning $=75$, Social Functioning $=90$, School Functioning $=95$ ). At posttreatment, the Physical Health and Emotional Functioning scores remained stable and the School Functioning (80) and Psychosocial Health (80) scales decreased at the clinically important level but remained above the chronic illness and population means. All other scores decreased slightly but not significantly.

\section{Attitudes towards Exercise}

Children's attitudes towards exercise were assessed via VASs at baseline and at the end of each phase (see Table 3). For the question that assessed how much the child enjoyed exercise, higher scores indicated more enjoyment. For the question that assessed how difficult exercise was for the child, higher scores indicated more difficulty. For Participant 1, scores across phases remained relatively stable, ranging from 46-56 for enjoyment and 31-36 for difficulty. Thus, Participant 1 consistently reported neutral ratings of enjoyment of and some difficulty with exercise. Participant 2 initially reported a 43 for enjoying exercise but scores then increased and remained stable between 98-99. She reported no difficulty exercising across phases. Participant 3 exhibited the most variability in scores with enjoyment ranging from 78-94 across phases and difficulty initially low (7) then increasing to a high of 68 before decreasing again.

Table 3

VAS Scores across Phases for Amount Exercise is Enjoyed and Difficulty of Exercise

Pre Baseline Treatment 1 Reversal Treatment 2

\section{Participant 1}

$\begin{array}{llllll}\text { Enjoy Exercise } & 46 & 46 & 49 & 47 & 56 \\ \text { Difficulty } & 34 & 34 & 32 & 36 & 31\end{array}$

Participant 2

$\begin{array}{lccccc}\text { Enjoy Exercise } & 43 & 98 & 100 & 100 & 99 \\ \text { Difficulty } & 1 & 1 & 1 & 0 & 1\end{array}$

Participant 3

$\begin{array}{lccccc}\text { Enjoy Exercise } & 94 & 83 & 93 & 87 & 78 \\ \text { Difficulty } & 7 & 68 & 45 & 30 & 23\end{array}$




\section{Discussion}

The primary objective of this study was to assess the efficacy of a token economy reinforcement system on increasing aerobic exercise in children with cystic fibrosis. Although results for the three participants varied, the reversal design indicated that exercise behavior was controlled by the token economy. Specifically, exercise increased when the token economy was in place and exercise was low when the token economy was not in place. Thus, the results of the current study indicate that token economies are an effective technique to increase exercise with children with cystic fibrosis. This is consistent with results of past studies that have examined the use of token economies to increase exercise with other chronic populations (e.g., Epstein et al., $1982 ; 1983)$, as well as the results of studies that have used token economies to increase adherence to other aspects of the cystic fibrosis treatment regimen (e.g., Stark et al., 1990).

Of the three participants, Participant 2 most strongly demonstrated the effectiveness of the token economy. This participant consistently exercised every other day when the token economy was in place and consistently did not exercise when the token economy was not being used. Participant 1 also consistently exercised during the treatment phase and consistently did not exercise during the baseline and reversal phases; however, her exercise during the return to treatment phase was significantly higher than during the initial treatment phase. As previously mentioned, the increase in exercise coincided with the parent changing the reward from small, medium, and large prizes to a monetary reward. Specifically, the parent reportedly told the participant that the amount of money the participant could earn was dependent on the amount of exercise she performed during the return to treatment phase. Although this change could be viewed as a change in one of the study variables, it actually represents how the token economy is best used in practice. In order for a token economy to be effective, the individual must be motivated by the rewards (Barkley, 1987). Thus, it is not uncommon for the rewards to require modification as the individual's desires change in order for the token economy to continue to be reinforcing. In fact, as part of the training for the token economy, parents were instructed to sit down with their child and develop a new prize list if the child no longer seemed motivated by the current rewards. The increase in amount of exercise from the treatment to the return to treatment phase for Participant 1 speaks to the importance of selecting the rewards for the target behavior. It is essential to ensure that the rewards are reinforcing for the child in order for the token economy to be effective. Moreover, the better the reward matches the child's desires, the more likely he or she is to exercise.

In comparison to the other two participants, data for Participant 3 demonstrated less stability. Although the token economy was effective in increasing the amount of exercise over the baseline rate, the amount of exercise completed during each exercise session was not as consistent as that of the other two participants. Of note, unlike the other participants, Participant 3 was involved in exercise prior to the study. Specifically, during the first two conditions, Participant 3 was enrolled in a weekly dance class. Thus, it was predicted that her data during the treatment condition would have a similar pattern as the baseline data, but shifted up due to the participant completing exercise at the prescribed level on non-dance days. The shift up did occur, but the pattern was inconsistent. There are several possible explanations for the inconsistency. First, there was some discrepancy between the child and parent report about the amount of exercise the child completed. Because the parent worked and could not always personally 
monitor the child during exercise, there were a few occasions when the child would report exercise and the parent would either report less exercise or no exercise because no adult witnessed the exercise. Additionally, the parent and child at times disagreed about the child's exertion level. For example, the child might have reported riding a bike for $30 \mathrm{~min}$, but the parent reported that the child went for a 10 min bike ride and then rode slowly around in the driveway for $20 \mathrm{~min}$. Consequently, the child may have thought that she had met the recommended exercise goal, but the parent did not agree. In fact, given child report only (instead of parent and child agreement which was used to graph the data), the amount of exercise would be more consistent. Aside from disagreements between parent and child, the child's age may have played a role. Participant 3 was younger than the other two participants. Whereas the older children may be better at self-regulating their exercise, younger children may require additional guidance. This guidance could come in the form of parental monitoring or child participation in structured exercise activities (e.g., sports teams).

One final thing to note about Participant 3's data is that there was a significant increase in amount of exercise that occurred during the middle of the return to treatment phase. At that point in the phase, the child began swimming for several hours/day at her grandmother's house. This child reported that she greatly enjoyed swimming and it is likely that she would have done this particular exercise regardless of whether the token economy was in place. Past studies have indicated that children prefer to have a choice in exercise (Epstein et al., 1982). In the current investigation, it appears that the type of exercise the child participates in is an important variable and that exercise can be something that the child has intrinsic motivation to do if it is a preferred activity. For this child, swimming was only an option during the summer, so she most likely would require extrinsic motivation to do other forms of exercise for the duration of the year. Thus, a token economy may be necessary to reinforce a child be for engaging in a non-preferred activity or trying new types of exercise.

As children exercised more regularly during the course of the study, children's quality of life and attitudes towards exercise were expected to improve. Participant 1, who had the lowest initial child self-report and parent-proxy report PedsQL ${ }^{\mathrm{TM}} 4.0$ scores, demonstrated the highest level of improvement at post-treatment when compared to her baseline scores. This child exhibited almost no exercise at baseline and it is likely that regular exercise helped to improve her scores on the quality of life measure. Mixed results were found for Participant 2. The child reported an increase in quality of life across most aspects measured by the PedsQL ${ }^{\mathrm{TM}} 4.0$, but parent reported little change from baseline to post-treatment. However, scores for Participant 2 were initially high; in fact, most scores were above the means for the general population. Thus, little positive change was possible due to a ceiling effect. Although Participant 3 reported a decrease in most areas of quality of life, her scores remained in the expected range for children with chronic illnesses. Of note, parent proxy-report scores for this participant remained relatively stable. Overall, results were mixed, with one participant demonstrating improvement in quality of life, one remaining relatively stable and well above the expected means for children with a chronic illness, and one demonstrating a slight decrease in quality of life for child-report but no change for parent-proxy report. Further research is necessary to determine the positive effects of regular exercise on quality of life. 
For attitudes towards exercise, it was expected that enjoyment of exercise would increase while difficulty of exercise would decrease. Scores for how much the child enjoyed exercise were relatively stable for all three participants. Overall, one participant reported neutral scores for enjoyment of exercise whereas the other two reported a high level of enjoyment of exercise with one participant reporting an increase in enjoyment of exercise and one reporting variable levels of enjoyment across the study. Scores for how difficult exercise was for the child were stable for two participants and variable for one participant. Taken as a whole, one participant reported almost no difficulty exercising, one reported some difficulty exercising, and one reported little to moderate difficulty exercising. Thus, mixed results were found for children's attitudes towards exercise. These results suggest that for some children, exercise itself may become intrinsically rewarding; however, some children may continue to require external rewards to maintain regular exercise.

Medical monitoring was conducted in order to ensure that the treatment did not negatively impact the participants' health. Even though there was some variability in health measures from baseline to post-treatment, with some measures improving slightly and some decreasing slightly, it appears as if the addition of regular aerobic exercise did not negatively impact the health of the three participants. More importantly, lung functioning and BMI, two critical factors in the health of children with cystic fibrosis, remained stable, with one participant demonstrating an increase in BMI over the short duration of the study. Because exercise is commonly associated with weight loss, and weight loss is not a desired outcome for children with cystic fibrosis, it is noteworthy that weight for children in this study remained stable. Given past research suggesting that over time, children's health may improve with regular exercise (e.g., Edlund et al., 1986), it will be important for future studies to examine the long-term health benefits of exercise on children with cystic fibrosis.

A significant strength of this investigation is that it begins to fill a void in the literature. Although several studies have examined behavioral techniques to increase adherence to other aspects of the cystic fibrosis treatment regimen, currently there are only two studies (Hobbs et al., 1988; Tuzin, 1983) that examine behavioral interventions for increasing exercise for children with cystic fibrosis and neither of these studies has been published (Bernard \& Cohen, 2004). Given the importance of lung functioning on longevity with this population, additional studies examining the increase of aerobic exercise are essential. An additional strength of the intervention used in this study is that it appears to be easy for parents to learn and utilize. Due to the complicated medical regimen of children with cystic fibrosis, it is important that interventions designed to increase adherence to treatment recommendations alleviate not exacerbate the problem. Token economies seem to be a good treatment option for increasing adherence to exercise because they take little time to use on a daily basis and yet still are powerful motivators for children. This is the ideal combination for an intervention with this population.

Several limitations of the current investigation should be noted. First, the sample size is small, which limits the generalizability of the study results. Also impacting the generalizability of the study is the uniformity of the sample. Although an attempt was made to have both males and females who ranged in age from 8-12 participate in the study, the sample was all Caucasian females with one 8-year-old and two 12-year-olds. However, this did provide additional internal 
validity to the study. A second limitation, which is inherent in many studies of this nature, is the possibility that demand characteristics may have influenced study results. Finally, even though a brief assessment of treatment integrity was conducted, it cannot be determined definitively that parent behavior (e.g., amount of encouragement given to exercise) was consistent across phases. Because this study was conducted in the community, control of this variable was difficult because measures used to assess parent behavior, aside from self-report, would have been a possible confound. Further, although conducting the study in the participant's home bolsters the current study's external validity, as a result, there was less control of parent behavior. A more detailed assessment of treatment integrity would have been helpful in ruling out variance in parent behavior as a possible confound or to illuminate any changes in parent behavior that may be inherent in the parent implementing an intervention of this nature.

Future research in this area should focus on replication of the study results with larger samples and broader populations. Because the current investigation was with females who ranged in age from 8-12 years, it will be important to examine this technique with males and to replicate the study with a broader age range. Of note, it is expected that the token economy will be equally effective with males and females; however, given that males between the ages of 6 and 15 years appear to have better pulmonary functioning than females in the same age range (Rosenfeld, Davis, FitzSimmons, Pepe, \& Ramsey, 1997), it is important to assess the necessity and utility of this treatment technique with child and adolescent males. Additionally, this study included individuals with mild impairment in lung functioning; future research should explore the possibility of using this technique to increase exercise in children with moderate to severe impairment in lung functioning. Once the effectiveness of token economies in increasing exercise in children with cystic fibrosis is established, multiple-component treatments that include token economies could be examined. In fact, it is possible that a combination of behavioral techniques potentially could be the most beneficial in increasing exercise with this population. Finally, it will be important for future studies to include a follow-up period to determine if treatment gains maintain (i.e., the child continues to exercise regularly) and to assess the long-term health benefits of regular exercise with this population. Part of the followup should be to gradually fade out the token economy by shifting the rewards from parentdirected to child-directed in order to promote long-term lifestyle change in exercise behavior.

Overall, token economies appear to be a viable treatment technique for children with cystic fibrosis because they are relatively time effective and cost efficient. Moreover, token economies are easy to understand and implement. Given the extensive treatment regimen for children with cystic fibrosis, it is important for treatment to be beneficial without causing too many additional demands on the family or child. Token economies meet both of these criteria; they require little extra work on the part of the family and they effectively increase exercise. 


\section{References}

Alexander, A. B. (1983). The nature of asthma. In P. J. McGrath \& P. Firestone (Eds.), Pediatric and adolescent behavioral medicine: Issues in treatment (pp. 28-66). New York: Springer.

Alison, J. A., Donnelly, P. M., Lennon, M., Parker, S., Torzillo, P., Mellis, C., et al. (1994). The effect of a comprehensive, intensive inpatient treatment program on lung function and exercise capacity in patients with cystic fibrosis. Physical Therapy, 74, 583-591.

Anderson, B. J., Auslander, W. F., Jung, K. C., Miller, J. P., \& Santiago, J. V. (1990). Assessing family sharing of diabetes responsibilities. Journal of Pediatric Psychology, 15, 477-492.

Andreasson, B., Jonson, B., Kornfalt, R., Nordmark, E., \& Sandstrom, S. (1987). Long-term effects of physical exercise on working capacity and pulmonary function in cystic fibrosis. Acta Paediatrica Scandinavica, 76, 70-75.

Arnhold, R. G., Adebonojo, F. O., Callas, E. R., Callas, J., Carte, E., \& Stein, R. C. (1970). Patients and prescriptions: Comprehension and compliance with medical instructions in a suburban pediatric practice. Clinical Pediatrics, 9, 648-651.

Baldwin, D. R., Hill, A. L., Peckham, D. G., \& Knox, A. J. (1994). Effect of addition of exercise to chest physiotherapy on sputum expectoration and lung function in adults with cystic fibrosis. Respiratory Medicine, 88, 49-53.

Balfour-Lynn, I. M., Prasad, S. A., Laverty, A., Whitehead, B. F., \& Dinwiddie, R. (1998). Pediatric Pulmonology, 25, 278-284.

Barkley, R. A. (1987). Step five: When praise is not enough-poker chips and points. In Defiant Children (pp. 96-108). New York: Guilford.

Bernard, R. S., \& Cohen, L. L. (2004). Increasing adherence to cystic fibrosis treatment: A systematic review of behavioral techniques. Pediatric Pulmonology, 37, 8-16.

Bilton, D., Dodd, M. E., Abbot, J. V., \& Webb, A. K. (1992). The benefits of exercise combined with physiotherapy in the treatment of adults with cystic fibrosis. Respiratory Medicine, 86, 507-511.

Blomquist, M., Freyschuss, U., Wiman, L. G., \& Strandvik, B. (1986). Physical activity and self treatment in cystic fibrosis. Archives of Disease in Childhood, 61, 362-367.

Boas, S. R. (1997). Exercise recommendations for individuals with cystic fibrosis. Sports Medicine, 24, 17-37. 
Cerny, F. J., Cropp, G., J., \& Bye, M. R. (1984). Hospital therapy improves exercise tolerance and lung function in cystic fibrosis. American Journal of Diseases of Children, 138, 261265.

Coates, T. J., Jeffery, R. W., Slinkard, L. A., Killen, J. D., \& Danaher, B. G. (1982). Frequency of contact and monetary reward in weight loss, lipid change, and blood pressure reduction with adolescents. Behavior Therapy, 13, 175-185.

De Luca, R. V., \& Holborn, S. W. (1985). Effects of a fixed-interval schedule of token reinforcement on exercise with obese and non-obese boys. The Psychological Record, 35, $525-533$.

Doughty, A. H., \& Lattal, K. A. (2003). Response persistence under variable-time schedules following immediate and unsignalled delayed reinforcement. The Quarterly Journal of Experimental Psychology, 56B, 267-277.

Edlund, L. D., French, R. W., Herbst, J. J., Ruttenberg, H. D., Ruhling, R. O., \& Adams, T. D. (1986). Effects of a swimming program on children with cystic fibrosis. American Journal of Diseases of Children, 140, 80-83.

Elborn, S. (1998). The management of young adults with cystic fibrosis: 'genes, jeans and genies.' Disability and Rehabilitation, 20, 217-225.

Ensor, E., Humphreys, H., Peckham, D., Webster, C., \& Knox, A. J. (1996). Is Burkholderia (Pseudomonas) cepacia disseminated from cystic fibrosis patients during physiotherapy? Journal of Hospital Infection, 32(1), 9-15.

Epstein, L. H., Koeske, R., Zidansek, J., \& Wing, R. R. (1983). Effects of weight loss on fitness in obese children. American Journal of Diseases of Childhood, 137, 654-657.

Epstein, L. H., Valoski, A. M., Vara, L. S., McCurley, J., Wisniewski, L., Kalarchian, M. A., et al. (1995). Effects of decreasing sedentary behavior and increasing activity on weight change in obese children. Health Psychology, 14, 109-115.

Epstein, L. H., Wing, R. R., Koeske, R., Ossip, D., \& Beck, S. (1982). A comparison of life style change and programmed aerobic exercise on weight and fitness changes in obese children. Behavior Therapy, 13, 651-665.

Epstein, L. H., Wing, R. R., Woodall, K., Penner, B. C., Kress, M. J., \& Koeske, R. (1985). Brief report: Effects of family-based behavioral treatment on obese 5-to-8-year-old children. Behavior Therapy, 16, 205-212.

Fehrenbach, A. M., \& Peterson, L. (1989). Parental problem-solving skills, stress, and dietary compliance in phenylketonuris. Journal of Consulting and Clinical Psychology, 57, 237241. 
FitzSimmons, S. C. (1993). The changing epidemiology of cystic fibrosis. Journal of Pediatric Psychology, 122, 1-9.

Fong, S. L., Dales, R. E., \& Tierney, M. G. (1990). Compliance among adults with cystic fibrosis. DICP, The Annals of Pharmacotherapy, 24, 689-691.

Freund, A., Johnson, S. B., Silverstein, J., \& Thomas, J. (1991). Assessing daily management of childhood diabetes using 24-hour recall interviews: Reliability and stability. Health Psychology, 10, 200-208.

Friedman, I. M., \& Litt, I. F. (1987). Adolescents' compliance with therapeutic regimens: Psychological and social aspects and intervention. Journal of Adolescent Health Care, 8, $52-65$.

Geiger, G., Todd, D. D., Clark, H. B., Miller, R. P., \& Kori, S. H. (1992). The effects of feedback and contingent reinforcement on the exercise behavior of chronic pain patients. Pain, 49, 179-185.

Gordis, L., Markowitz, M., \& Lilienfeld, A. M. (1969). Why patients don't follow medical advice: A study of children on long-term antistreptococcal prophylaxis. Journal of Pediatrics, 75, 957-968.

Greenan-Fowler, E., Powell, C., \& Varni, J. W. (1987). Behavioral treatment of adherence to therapeutic exercise by children with hemophilia. Archives of Physical Medicine and Rehabilitation, 68, 846-849.

Gudas, L. J., Koocher, G. P., \& Wypij, D. (1991). Perceptions of medical compliance in children and adolescents with cystic fibrosis. Journal of Developmental and Behavioral Pediatrics, 12, 236-242.

Gurwitz, D., Corey, M., Francis, P. W., Crozier, D., \& Levison, H. (1979). Perspectives in cystic fibrosis. The Pediatric Clinics of North America, 26, 603-615.

Hagopian, L. P., \& Thompson, R. H. (1999). Reinforcement of compliance with respiratory treatment in a child with cystic fibrosis. Journal of Applied Behavior Analysis, 32, 233236.

Haynes, R. B., (1979). Introduction. In R. B. Haynes, D. W. Taylor, \& D. L. Dackett (Eds.), Compliance in health care (pp. 1-7). Baltimore: Johns Hopkins University Press.

Heijerman, H. G. (1993). Chronic obstructive lung disease and respiratory function: The role of nutrition and exercise training in cystic fibrosis. Respiratory Medicine, 87(Suppl. B), 4951. 
Hobbs, S. A., Strutton, R., \& Kramer, J. C. (1988, September). Outcome of a home-based behavioral exercise program in the treatment of cystic fibrosis. Paper presented at the North American Cystic Fibrosis Conference, Orlando, FL.

Hodges, P., Sauriol, D., Mann, S. P., Reichart, A., Grace, R. M., Talbot, R. W., et al. (1984). Nutrient intake of patients with cystic fibrosis. Journal of the American Dietetic Association, 84, 664-669.

Homnick, D. N., \& Marks, J. H. (1998). Exercise and sports in the adolescent with chronic pulmonary disease. Adolescent Medicine, 9, 467-479.

Hudson, J., Fielding, D., Jones, S., \& McKendrick, T. (1987). Adherence to medical regime and related factors in youngsters on dialysis. British Journal of Clinical Psychology, 26, 6162.

Ievers, C. E., Brown, R. T., Drotar, D., Caplan, D., Pishevar, B. S., \& Lambert, R. G. (1999). Knowledge of physician prescriptions and adherence to treatment among children with cystic fibrosis and their mothers. Journal of Developmental and Behavioral Pediatrics, 20, 335-343.

Jason, L. A., \& Brackshaw, E. (1999). Access to TV contingent on physical activity: effects on reducing TV-viewing and body-weight. Journal of Behavior Therapy and Experimental Psychiatry, 30, 145-151.

Johnson, W. G., Hinkle, L. K., Carr, R. E., Anderson, D. A., Lemmon, C. R., Engler, L. B., et al. (1997). Dietary and exercise interventions for juvenile obesity: Long-term effect of behavioral and public health models. Obesity Research, 5, 257-261.

Karlberg, J., Kwan, C., Gelander, L., \& Albertsson-Wikland, K. (2003). Pubertal growth assessment. Hormone Research, 60(Suppl. 1), 27-35.

Kazdin, A. E. (1998). The case study and single-case research designs. In Research design in clinical psychology (pp.202-244). Boston: Allyn and Bacon.

Knudson, R. J., Lebowitz, M. D., Holberg, C. J., \& Burrows, B. (1983). Changes in the normal maximal expiratory flow-volume curve with growth and aging. American Review of Respiratory Disorders, 127, 725-734.

Kraemer, R., Rudeberg, A., Hadorn, B, \& Rossi, E. (1978). Relative underweight in cystic fibrosis and its prognostic value. Acta Paediatrica Scandinavica, 67, 33-37.

Kuczmarski, R. J., Ogden, C. L., Grummer-Strawn, L. M., Flegal, K. M., Guo, S. S., Wei, R. et al. (2000). CDC growth charts: United States. Advance Data, 314, 1-27. 
La Greca, A. M., \& Schuman, W. B. (1995). Adherence to prescribed medical regimens. In M. C. Roberts (Ed.), Handbook of pediatric psychology: Second edition (pp. 55-83). New York: The Guilford Press.

Lai, H., Corey, M., FitzSimmons, S., Kosorok, M. R., \& Farrell, P. M. (1999). Comparison of growth status of patients with cystic fibrosis between the United States and Canada. American Journal of Clinical Nutrition, 69, 531-538.

Lapmann, R. M (1997). Exercise prescription for chronically ill patients. American Family Physician, 55, 2185-2192.

Ledson, M. J., Gallagher, M. J., Corkill, J. E., Hart, C. A., \&Walshaw, M. J. (1998). Cross infection between cystic fibrosis patients colonised with Burkholderia cepacia. Thorax, $53,432-436$.

Litt, I. F., Cuskey, W. R., \& Rudd, S. (1980). Identifying adolescents at risk for noncompliance with contraceptive therapy. Journal of Pediatrics, 96, 742-745.

MacDonald, A., Holden, C., \& Harris, G. (1991). Nutritional strategies in cystic fibrosis: current issues. Journal of the Royal Society of Medicine, 84 (Suppl. 18), 28-35.

Marshall, S. G., Rosenfeld, M., \& Ramsey, B. W. (2000). Pediatrics. In M. E. Hodson, \& D. M., Geddes (Eds.), Cystic fibrosis (pp. 211-217). New York: Oxford University Press.

Meyers, A., Dolan, T. F., \& Mueller, D. (1975). Compliance and self-medication in cystic fibrosis. American Journal of Diseases in Children, 129, 1011-1013.

Moorcroft, A. J., Dodd, M. E., \& Webb, A. K. (1998). Exercise limitations and training for patients with cystic fibrosis. Disability and Rehabilitation, 20, 247-253.

Moore, L. L., Gao, D., Bradlee, M. L., Cupples, L. A., Sundarajan-Ramamurti, A., Proctor, M. H. et al. (2003). Does early physical activity predict body fat change throughout childhood? Preventive Medicine, 37, 10-17.

Narang, I., Pike, S., Rosenthal, M., Balfour-Lynn, I.M., \& Bush, A. (2003). Three-minute step test to assess exercise capacity in children with cystic fibrosis with mild lung disease. Pediatric Pulmonology, 35, 108-133.

Neale, A. V., Singleton, S. P., Dupuis, M. H., \& Hess, J. W. (1990). The use of behavioral contracting to increase exercise activity. American Journal of Health Promotion, 4, 441447.

NIH (1997). Genetic testing for cystic fibrosis. National institutes of health consensus statement online, April 14-16 ${ }^{\text {th }}, 15(4), 1-37$. Retrieved April 25, 2002, from http://odp.od.nih.gov/consensus/cons/106/106_statement.htm 
Oldridge, N. B. (1982). Compliance and exercise in primary and secondary prevention of coronary heart disease: A review. Preventive Medicine, 11, 56-70.

Oldridge, N. B., \& Jones, N. L. (1983). Improving patient compliance in cardiac exercise rehabilitation: Effects of written agreement and self-monitoring. Journal of Cardiac Rehabilitation, 3, 257-262.

Orenstein, D. M., Holt, L. S., Rebovich, P., Campbell, T., \& Nixon, P. (2002). Measuring ease of breathing in young patients with cystic fibrosis. Pediatric Pulmonology, 34, 473-477.

Parson, H. G., Beaudry, P., Dumas, A., \& Pencharz, P. B. (1983). Energy needs and growth in children with cystic fibrosis. Journal of Pediatric Gastroenterology and Nutrition, 2, 4449.

Passero, M. A., Remor, B., \& Salomon, J. (1981). Patient-reported compliance with cystic fibrosis therapy. Clinical Pediatrics, 20, 264-268.

Pike, S. E., Prasad, S. A., \& Balfour-Lynn, I. M. (2001). Effect of intravenous antibiotics on exercise tolerance (3-min step test) in cystic fibrosis. Pediatric Pulmonology, 32, 38-43.

Quittner, A. L., Opipari, L. C., Regoli, M. J., Jacobsen, J., \& Eigen, H. (1992). The impact of caregiving and role strain on family life: Comparisons between mothers of children with cystic fibrosis and match controls. Rehabilitation Psychology, 37, 289-304.

Ramsey, B. W., Farrel, P. M., Pencharz, P., \& the Consensus Committee. (1992). Nutritional assessment and management in cystic fibrosis: A consensus report. American Journal of Clinical Nutrition, 55, 108-116.

Robertson, R. R., Goss, F. L., Bell, J. A., Dixon, C. B., Gallagher, K. I., Lagally, K. M., et al. (2002). Self-regulated cycling using the children's OMNI Scale of Perceived Exertion. Medicine and Science in Sports and Exercise, 34, 1168-1175.

Robertson, R. R., Goss, F. L., Boer, N. F., Peoples, J. A., Foreman, A. J., Dabayebeh, I. M., et al. (2000). Children's OMNI Scale of Perceived Exertion: Mixed gender and race validation. Medicine and Science in Sports and Exercise, 32, 452-458.

Rosenfeld, M., Davis, R., FitzSimmons, S., Pepe, M., \& Ramsey, B. (1997). Gender gap in cystic fibrosis mortality. American Journal of Epidemiology, 145, 794-803.

Salh, W., Bilton, D., Dodd, M., \& Webb, A. K. (1989). Effect of exercise and physiotherapy in aiding sputum expectoration in adults with cystic fibrosis. Thorax, 44, 1006-1008.

Sarinas, P. S., Robinson, T. E., Clark, A. R., Canfield, J., Chitkara, R. K., \& Fick, R. B. (1998). Inspiratory flow rate and dynamic lung function in cystic fibrosis and chronic obstructive lung diseases. Chest, 114, 988-992. 
Schafer, L. C., Glasgow, R. E., \& McCaul, K. D. (1982). Increasing the adherence of diabetic adolescents. Journal of Behavioral Medicine, 5, 353-362.

Schneiderman-Walker, J., Pollock, S. L., Corey, M., Wilkes, D. D., Canny, G. J., Pedder, L., et al. (2000). A randomized controlled trial of a 3-year home exercise program in cystic fibrosis. Journal of Pediatrics, 136(3), 304-310.

Schultz, S. J. (1993). Educational and behavioral strategies related to knowledge of and participation in an exercise program after cardiac positron emission tomography. Patient Education and Counseling, 22, 47-57.

Singer, L. T., Nofer, J. A., Benson-Szekely, L. J., \& Brooks, L. J. (1991). Behavioral assessment and management of food refusal in children with cystic fibrosis. Journal of Developmental and Behavioral Pediatrics, 12, 115-120.

Singleton, S. P., Neale, A. V., Hess, J. W., \& Dupuis, M. H. (1987). Behavioral contracting in an urban health promotion project. Evaluation \& The Health Professions, 10, 408-437.

Skinner, B. F. (1936). The effect on the amount of conditioning of an interval of time before reinforcement. Journal of General Psychology, 14, 279-295.

Smith, S. D., Rosen, D., Trueworthy, R. C., \& Lowman, J. T. (1979). A reliable method for evaluating drug compliance in children with cancer. Cancer, 43, 169-173.

Stanbrook, M. B, Corey, M., \& D. Elizabeth Tullis, D. E. (2004). The repeatability of forced expiratory volume measurements in adults with cystic fibrosis. Chest, 125, 150-155.

Stanghelle, J. K., Winnem, M., Roaldsen, K., de Wit, S., Notgewitch, J. H., \& Nilsen, B. R. (1988). Young patients with cystic fibrosis: Attitude toward physical activity and influence on physical fitness and spirometric values of a 2-week training course. International Journal of Sports Medicine, 9 (Suppl.), 25-31.

Stark, L. J., Bowen, A. M., Tyc, V. L., Evans, S., \& Passero, M. (1990). A behavioral approach to increasing calorie consumption in children with cystic fibrosis. Journal of Pediatric Psychology, 15, 309-326.

Stark, L. J., Jelalian, E., \& Miller, D. L. (1995). Cystic Fibrosis. In M. C. Roberts (Ed.), Handbook of Pediatric Psychology: Second Edition (pp. 241-262). New York: The Guilford Press.

Stark, L. J., Knapp, L. G., Bowen, A. M., Powers, S. W., Jelalian, E., Evans, S., et al. (1993). Increasing calorie consumption in children with cystic fibrosis: Replication with 2-year follow-up. Journal of Applied Behavior Analysis, 26, 435-450.

Stark, L. J., Miller, S. T., Plienes, A. J., \& Drabman, R. S. (1987). Behavioral contracting to increase chest physiotherapy. Behavior Modification, 11, 75-86. 
Stark, L. J., Mulvhill, M. M., Powers, S. W., Jelalian, E., Keating, K., Creveling, et al. (1996). Behavioral intervention to improve calorie intake of children with cystic fibrosis: treatment versus wait list control. Journal of Pediatric Gastroenterology and Nutrition, 23, 240-253.

Stark, L. J., Powers, S. W., Jelalian, E., Rape, R. N., \& Miller, D. L. (1994). Modifying problematic mealtime interactions of children with cystic fibrosis and their parents via behavioral parent training. Journal of Pediatric Psychology, 19, 751-768.

Stettler, N., Kawchak, D. A., Boyle, L. L., Propert, K. J., Scanlin, T. F., Stallings, V. A., et al. (2000). Prospective evaluation of growth, nutritional status, and body composition in children with cystic fibrosis. American Journal of Clinical Nutrition, 72, 407-413.

Sutphin, G., Byrne, T., \& Poling, A. (1998). Response acquisition with delayed reinforcement: A comparison of two-lever procedures. Journal of the Experimental Analysis of Behavior, 69, 17-28.

Thomas, J., Cook, D. J., \& Brooks, D. (1995). Chest physical therapy management of patients with cystic fibrosis. American Journal of Respiratory and Critical Care Medicine, 151, 846-850.

Tuzin, B. J. (1983). A behavioral intervention to increase the physical activity of children with cystic fibrosis: An objective evaluation. Unpublished master's thesis, San Diego State University, San Diego, California.

Utter, A. C., Robertson, R. J., Nieman, D. C., \& Kang, J. (2002). Children's OMNI Scale of Perceived Exertion: Walking/running evaluation. Medicine and Science in Sports and Exercise, 34, 139-144.

Varni, J. W., Burwinkle, T. M., Seid, M., \& Skarr, D. (2004). The PedsQL TM 4.0 as a pediatric population health measure: Feasibility, reliability, and validity. Ambulatory Pediatrics, 3, 329-341.

Varni, J. W., Seid, M., Knight, T. S., Uzark, K., \& Szer, I. S. (2002). The PedsQL ${ }^{\text {тM }} 4.0$ Generic Core Scales: Sensitivity, responsiveness, and impact on clinical decision-making. Journal of Behavioral Medicine, 25, 175-193.

Varni, J. W., Seid, M., \& Kurtin, P. S. (2001). The PedsQL ${ }^{\text {TM }}$ 4.0: Reliability and validity of the Pediatric Quality of Life Inventory ${ }^{\mathrm{TM}}$ Version 4.0 Generic Core Scales in healthy and patient populations. Medical Care, 39, 800-812.

Walters, S. (2000). Clinical epidemiology of cystic fibrosis. In M. E. Hodson, \& D. M., Geddes (Eds.), Cystic fibrosis (pp. 2-12). New York: Oxford University Press.

Webb, A. K., Dodd, M. E., \& Moorcroft, J. (1995). Exercise and cystic fibrosis. Journal of the Royal Society of Medicine, 88(Suppl. 25), 30-36. 
Webb, A. K., \& Govan, J. R. (1998). Burkholderia cepacia: Another twist and a further threat. Thorax, 53, 333-334.

Zach, M., Oberwaldner, B., \& Hausler, F. (1982). Cystic fibrosis: Physical exercise versus chest physiotherapy. Archives of Disease in Children, 57, 587-589. 
Appendix A: Background Information Form

\section{Background Information Form}

What is your relation to the child?

Your gender (circle one): male female

Your race?

Your date of birth?

Your education (highest grade completed/degree)?

Spouse's education (highest grade completed/degree)?

Your occupation?

Spouse's occupation?

Total annual family income (circle one of the following):

\$0-9,999 10-14,999 $\quad 15-24,999 \quad 25-39,999 \quad 40-59,000 \quad 60-99,999 \quad 100+$

What is the gender of this child (circle one): male female

Child's race?

Child's date of birth?

List the family members that currently live at home with the child: 
Appendix B: Exercise Diary-Parent

\begin{tabular}{|c|c|c|c|c|c|}
\hline \multicolumn{6}{|c|}{ Exercise Diary-Parent Form (Baseline) } \\
\hline Date & $\begin{array}{l}\text { Type of } \\
\text { Exercise }\end{array}$ & $\begin{array}{l}\text { Min Spent } \\
\text { Exercising }\end{array}$ & Consequence & $\begin{array}{c}\text { Pedometer } \\
\text { Reading }\end{array}$ & Hours Worn \\
\hline $10 / 15 / 02$ & Jogging & 25 & Eat Dinner & $\begin{array}{c}9,752 \text { steps/ } \\
1.8 \text { miles }\end{array}$ & 5 \\
\hline & & & & & \\
\hline & & & & & \\
\hline & & & & & \\
\hline & & & & & \\
\hline & & & & & \\
\hline & & & & & \\
\hline & & & & & \\
\hline & & & & & \\
\hline & & & & & \\
\hline & & & & & \\
\hline & & & & & \\
\hline & & & & & \\
\hline & & & & & \\
\hline & & & & & \\
\hline & & & & & \\
\hline & & & & & \\
\hline & & & & & \\
\hline & & & & & \\
\hline
\end{tabular}




\begin{tabular}{|c|c|c|c|c|c|c|}
\hline \multicolumn{7}{|c|}{ Exercise Diary-Parent Form (Treatment) } \\
\hline Date & $\begin{array}{l}\text { Type of } \\
\text { Exercise }\end{array}$ & $\begin{array}{c}\text { Min } \\
\text { Exercised }\end{array}$ & Consequence & $\begin{array}{l}\text { Points } \\
\text { Earned }\end{array}$ & $\begin{array}{c}\text { Pedometer } \\
\text { Reading }\end{array}$ & $\begin{array}{l}\text { Hours } \\
\text { Worn }\end{array}$ \\
\hline $10 / 15 / 02$ & Jogging & 25 & Ice cream cone & 2 & $\begin{array}{c}9,752 / 1.8 \\
\text { miles }\end{array}$ & 5 \\
\hline & & & & & & \\
\hline & & & & & & \\
\hline & & & & & & \\
\hline & & & & & & \\
\hline & & & & & & \\
\hline & & & & & & \\
\hline & & & & & & \\
\hline & & & & & & \\
\hline & & & & & & \\
\hline & & & & & & \\
\hline & & & & & & \\
\hline & & & & & & \\
\hline & & & & & & \\
\hline & & & & & & \\
\hline & & & & & & \\
\hline & & & & & & \\
\hline & & & & & & \\
\hline
\end{tabular}


Appendix C: Exercise Diary-Child

\begin{tabular}{|c|c|c|c|}
\hline \multicolumn{4}{|c|}{ Exercise Diary-Child Form (Baseline) } \\
\hline Date & Type of Exercise & Min Spent Exercising & Exertion Rating \\
\hline $10 / 15 / 02$ & Jogging & 25 & 7 \\
\hline & & & \\
\hline & & & \\
\hline & & & \\
\hline & & & \\
\hline & & & \\
\hline & & & \\
\hline & & & \\
\hline & & & \\
\hline & & & \\
\hline & & & \\
\hline & & & \\
\hline & & & \\
\hline & & & \\
\hline & & & \\
\hline & & & \\
\hline & & & \\
\hline & & & \\
\hline & & & \\
\hline
\end{tabular}




\begin{tabular}{|c|c|c|c|c|}
\hline \multicolumn{5}{|c|}{ Exercise Diary-Child Form (Treatment) } \\
\hline Date & Type of Exercise & Min Exercised & Exertion Rating & Type of Reward \\
\hline 10/15/02 & Jogging & 25 & 7 & Ice cream cone \\
\hline & & & & \\
\hline & & & & \\
\hline & & & & \\
\hline & & & & \\
\hline & & & & \\
\hline & & & & \\
\hline & & & & \\
\hline & & & & \\
\hline & & & & \\
\hline & & & & \\
\hline & & & & \\
\hline & & & & \\
\hline & & & & \\
\hline & & & & \\
\hline & & & & \\
\hline & & & & \\
\hline & & & & \\
\hline & & & & \\
\hline
\end{tabular}


Appendix D: Children's Attitude Towards Exercise

How I Feel About Exercise

How much do you enjoy exercising?

Not at All

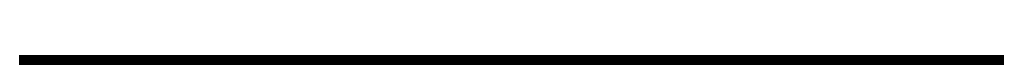

Very Much

How difficult is exercise for you to do?

Not at All

Very Difficult 


\section{Appendix E: Outline of Diet Recommendations}

\section{Dietary Recommendations}

I. Introduction
A. Children with cystic fibrosis (CF) have special dietary needs
B. How nutritional deficits occur

II. Diet recommendations

A. Daily requirements (e.g., high number of calories, increasing protein intake, increasing salt intake, increasing fat intake)

B. What foods may be problematic (e.g., some high-fat foods may be intolerable)

C. How often the child should eat

III. How to increase intake

A. How to boost calories per meal (e.g., using extra mayonnaise on sandwiches, putting butter on the bread of peanut butter and jelly sandwiches)

B. Use of dietary supplements

IV. Sample high calorie meals and snacks

V. How exercise may impact diet
A. Increase in calorie expenditure
B. How to compensate for the effects of exercise 
Appendix F: Topics of Token Economy Pamphlet

Trouble-Shooting Token Economies: A How-To Guide for Parents

1. My child is not motivated by the current rewards.

a. Sit down with your child and pick new rewards. It is very important that your child be motivated by the rewards, otherwise the token economy will not work. Children often loose interest in rewards (e.g., a new game came out that is much "cooler" than the old game on their reward list, a new cartoon and all the toys that go along with it just hit the store, etc.) and it may be necessary to sit down with your child every once in a while to pick new, exciting rewards.

b. Make the "big" rewards easier to get by reducing how many points they are worth. Then pick new "big” rewards. Your child may need something more exciting to shoot for!

c. You can also make all the rewards easier to get. It is possible that the rewards levels are too hard for your child to achieve or that the rewards he/she wants seem impossible to obtain. It is important for your child to feel that he/she will be able to get the rewards he/she wants after their hard work!

2. How to make the token economy system portable during a family vacation.

a. If you have enough room in the car/suitcase, take it all with you. Be sure to tell your child that he/she may not be able to get certain rewards until he/she returns home again if any of the rewards are only available at home.

b. Make a small token economy to take with you and put it up on the hotel room door, grandma's refrigerator, etc. Don't forget to take it home with you so that you can remember how many points the child earned! 
c. There are many exercises that your child can do while on vacation; however, it is important to make sure your child has a safe place to exercise while on vacation. You can always bring an exercise tape along or exercise with your child.

3. What do I do if my child is hospitalized?

a. If your child feels well enough and the doctor says it is okay for your child to exercise, bring the token economy to the hospital and do the same thing there that you would at home. (Hospitals typically have areas where patients can exercise.)

b. If your child's doctor says that exercise is not a good idea, put the token economy on hold. Then, when your child is feeling well enough, begin the token economy again.

c. If you do have to halt the token economy, be sure to begin it again when your child returns from the hospital. It may be necessary to pick new rewards to get your child motivated to exercise again.

4. My other children want token economies too!

a. Explain to your other children that the token economy is part of your child's (with CF) medical treatment. It may also be helpful to explain that exercise is difficult for your child with $\mathrm{CF}$ and that he/she needs extra encouragement to do it because it is so hard.

b. You could also start token economies for your other children. To do this, you would just need to pick out a behavior (e.g., making the bed, cleaning the room) that you would like to see that child do regularly and then set up goals and rewards like we did for your child with $\mathrm{CF}$. 
c. Explain that the token economy is something special that you do with your child with CF. Then, find something special (e.g., play a game) you can do with your other children so that they don't feel left out.

5. This system is too much work to maintain!

a. Remind yourself how important exercise is to your child's health.

b. Remember, all new things can be difficult. However, the token economy will quickly become a habit and will fit into the daily routine.

c. Keep in mind that the token economy is in place to help motivate your child to exercise. Once your child is exercising regularly, the token economy can be faded out.

6. My child says he/she does not want a token economy anymore.

a. Ignore any complaints and keep using the token economy. Children often "test the boundaries" to see if they can get out of doing something. They also can have bad days when they just don't seem to want to do anything. Since this is important to your child's health, it is important to keep using the system even if he/she complains about it.

b. Remind your child that exercise is important and that you want to use the token economy so that he/she gets rewarded for all of his/her hard work. You can also ask your child if he/she would like new rewards to make the token economy more exciting.

c. If all else fails, you can keep track covertly and continue to reward child when he/she has earned a reward. 


\section{Appendix G: Outline of Token Economy Instructions \\ Token Economy Instructions}

I. Introduction

A. What is a token economy?

B. How is it used to change behavior?

1. Used to motivate the child to try new or difficult behaviors

2. Must be used as a reward, not a rule to be followed or a punishment

II. Step-by-step: How to use the token economy

A. Set up the token economy

1. Ensure that parent and child understand the target behavior

2. Parent, child, and therapist choose small, immediate rewards

3. Parent, child, and therapist choose larger, delayed rewards

4. Assign point values to larger, delayed rewards

a. Rewards should vary in "value"

b. Ensure the child understands that he/she can save points for larger rewards if the child wishes

5. Ensure that the parent and child understand how points are spent

III. How to make it work

B. Consistency is key (make it part of the daily routine)

C. Place it in a prominent location

IV. Model appropriate use of the token economy 
REBECCA SUZANNE BERNARD

\section{Curriculum Vitae}

Work Address:

Home Address:

E-mail Address:

Telephone:

Date of Birth:
Sharp HealthCare

Psychology Services

Sharp Mesa Vista Hospital

7850 Vista Hill Ave.

San Diego, CA 92123

1240 India St., \#1510

San Diego, CA 92101

rebesoccer@aol.com

Work: (858) 715-8740

Home: (619) 804-7530

August 15, 1977

\section{EDUCATION AND TRAINING}

\section{Graduate:}

Ph.D. Clinical Psychology, West Virginia University, Morgantown, WV (expected 12/04)

Dissertation: Use of a Token Economy to Increase Exercise in Children with Cystic Fibrosis

M.A. Clinical Psychology, West Virginia University, Morgantown, WV (11/01)

Clinical Psychology, Washington State University, Pullman, WA (8/99-7/00)

Thesis: Parent Distress, Parent Behavior, and Infant Distress during Pediatric Immunizations

\section{Undergraduate:}

B.S. Psychology, Summa Cum Laude, University of California, San Diego, La Jolla, CA (3/99)

\section{HONORS AND AWARDS}

Vehse Travel Award (Oct. 2002)

HERF Graduate Student Scholarship Award, West Virginia University (2000-2001)

Graduate School Scholar Award, Washington State University (1999-2000)

Phi Beta Kappa (1999-present)

Golden Key Honors Society (1998-present) 
Psi Chi National Psychology Honors Society (1998-present)

Award for Excellence in Scholarship, University of California, San Diego (1999)

Outstanding Scholastic Achievement, University of California, San Diego (1999)

Alpha Chi Omega Book Scholarship (1999)

Provost's Honor Roll, University of California, San Diego (1995-1999)

\section{PROFESSIONAL ACTIVITIES}

Student Member, APA, Division 54, Society of Pediatric Psychology (4/01- present)

Student Member, Association for Advancement of Behavior Therapy (10/00 - present)

Member, WVU Department of Psychology Diversity Issues Committee, (2001-2002)

Member, WVU Department of Psychology Quality of Life Committee, (2001-2002)

Guest Speaker, Quin Curtis Center case conferences:

Bernard, R. S. \& O'Connell, C. (2002; October). Treating a brain injured client: How to modify behaviors they don't remember doing. Clinical Case Conference Presenter, West Virginia University.

Bernard, R. S. (2002; January). Stopping fire-setting, animal abuse, and aggression: Treatment of a child with conduct disorder. Clinical Case Conference Presenter, West Virginia University.

Bernard, R. S. (2001; August). Learning disabilities: Assessment and obstacles. Clinical Case Conference Presenter, West Virginia University.

\section{CLINICAL EXPERIENCE}

Sharp HealthCare Psychology Intern. (9/03-present; 40 hrs/wk)

Psychology Services, Sharp Mesa Vista Hospital \& Grossmont Hospital, San Diego, CA

Psychology Training Director: Ira Grossman, Ph.D., ABPP

Supervisors: Stu Bardach, LCSW; Sheryl Dagang Ph.D.; Sara Maltzman, Ph.D.; Marc Murphy, Ph.D.;

Cheryl Rode, Ph.D.

Completing three specialty rotations: Adolescent Partial Hospitalization Program, Child and Adolescent Inpatient Program, and Grossmont Behavioral Health Services. Responsibilities include conducting individual, family, group, and multi-family group therapy, case management, and participation in multidisciplinary patient team meetings and treatment conferences for children and adolescents with a variety of psychological disorders in both inpatient and partial hospitalization settings. Duties also include consultation/liaison services within the hospital, evaluation and consultation in the emergency department, and individual and group therapy with a wide age range and variety of dual diagnoses of psychological and medical illnesses. Additional responsibilities include psychodiagnostic assessment and outpatient therapy. 
Behavioral Medicine Practicum Student. (7/02-6/03; $20 \mathrm{hrs} / \mathrm{wk})$

Department of Behavioral Medicine, Chestnut Ridge Hospital, Morgantown, WV

Supervisor: Tandy McClung, Ed.D.

Conducted outpatient therapy with children and adolescents exhibiting a variety of internalizing and externalizing psychological disorders (e.g., mood disorders, ADHD). Specialized experience with children experiencing Post Traumatic Stress Disorder due to physical or sexual abuse. Additionally, led inpatient cognitive-behavioral groups (e.g., Assertiveness Training, Progressive Muscle Relaxation, Rational Emotive Therapy) on the inpatient adolescent unit, the inpatient dual diagnosis adult unit, and the inpatient adult unit.

Behavior Modification Team Practicum Student. (8/02-6/03; 5-10 hrs/wk)

Quin Curtis Center, West Virginia University, Morgantown, WV

Supervisor: Cheryl McNeil, Ph.D.

Conducted Parent Child Interaction Therapy (PCIT) with parents of children exhibiting disruptive behavior disorders. Also, expanded on previous training in individual and family outpatient therapy with children with a variety of psychological disorders (e.g., adjustment disorder).

Volunteer Camp Counselor at Pediatric Burn Camp. (6/03/02-6/07/02)

Sponsored by the Western Pennsylvania Hospital, Camp Kon-O-Kwee, Fombell, PA

Supervisor: Christina Adams, Ph.D.

Responsibilities included supervision of children (ages 7-17) in typical camp activities, assisting in the implementation of a positive behavior support program, and managing problem behavior. Led small group discussions about coping strategies for dealing with difficult situations associated with being burned (e.g., children teasing).

Volunteer Cognitive Behavior Therapist. (8/01-8/02; 5-7 hrs/wk)

Department of Behavioral Medicine, Chestnut Ridge Hospital, Morgantown, WV

Supervisor: Tandy McClung, Ed.D.

Conducted group cognitive-behavioral therapy (i.e., Problem Solving, Rational Emotive Therapy, and Suicide Prevention) and individual therapy on the inpatient adolescent unit. Additionally, conducted individual therapy with adolescents in a dual diagnosis inpatient treatment program.

Adult, Adolescent, and Child Assessment and Treatment Team. (8/01-8/02; 7-10 hrs/wk)

Quin Curtis Center, West Virginia University, Morgantown, WV

Supervisor: Martin Boone, Ph.D.

Assessed learning disabilities and ADHD in child and adolescent populations. Gained experience with neuropsychological assessment. Additionally, trained in therapeutic techniques for children and adults with a variety of psychological disorders in an outpatient clinical setting (e.g., anxiety disorders, mood disorders, disorders due to medical conditions).

Practicum Student Therapist and Clinic Co-Administrator. (7/01-8/02; $20 \mathrm{hrs} / \mathrm{wk})$

Quin Curtis Center, West Virginia University, Morgantown, $W V$

Supervisor: Jeannie Sperry, Ph.D.

Conducted administrative duties necessary to run a psychology training clinic. Also used various therapy techniques and assessment tools with clients ranging from children to adults with a variety of psychological disorders (e.g., anxiety disorders, adjustment disorders). Participated in community outreach services to help make the public aware of available psychological services. 
Pediatric and General Child Psychology Team Therapist. (8/00-6/01; 5-7 hrs/wk)

Quin Curtis Center, West Virginia University, Morgantown, WV

Supervisor: Lindsey Cohen, Ph.D.

Observed and assisted in treatment planning for pediatric cases. Used various therapy techniques (e.g., parent training) and assessment tools with a variety of child and adolescent clients (e.g., Oppositional Defiant Disorder, ADHD).

Learning Disabilities Practicum Student. (1/00 - 7/00; $5 \mathrm{hrs} / \mathrm{wk})$

Department of Psychology, Washington State University, Pullman, WA

Supervisor: Maureen Schmitter-Edgecombe, Ph.D.

Conducted learning disability evaluations using standardized assessment measures (e.g., WAISIII, WJ-III) on clients presenting to the psychology clinic.

Discrete Trial Therapist. (4/98-8/99; $20 \mathrm{hrs} / \mathrm{wk})$

San Diego, $C A$

Employed as a discrete trial therapist for children with autism. Duties included administration of a Lovaas based training protocol emphasizing instruction in academic, social, and self-care skills.

\section{TEACHING EXPERIENCE}

Instructor, Controversial Issues in Psychology. (1/03-5/03)

Department of Psychology, West Virginia University, Morgantown, West Virginia Supervisor, Lindsey Cohen, Ph.D.

Designed this undergraduate level course. Responsible for choosing a text, creating a syllabus, preparing and delivering lectures, creating assignments and exams, and grading all work.

Instructor, Research Methods. (8/00- 5/01)

Department of Psychology, West Virginia University, Morgantown, West Virginia Supervisor: Lindsey Cohen, Ph.D.

Taught three sections of an undergraduate level class. Responsible for preparing and delivering lectures, creating examinations, and grading APA style research projects.

Teaching Assistant, Introduction to Clinical Psychology. (8/02-present)

Department of Psychology, West Virginia University, Morgantown, West Virginia

Supervisor: Barry Edelstein, Ph.D.

Taught weekly sessions with pairs of first year graduate students about client interviewing skills.

Responsibilities included reviewing videotapes of client-therapist role plays and providing feedback and instruction.

Teaching Assistant, Child Behavior Modification. (1/02-5/02)

Department of Psychology, West Virginia University, Morgantown, West Virginia

Supervisor: Cheryl McNeil, Ph.D.

Conducted skills check-outs (e.g., setting up a token economy) with first and second year

graduate students. Duties also included grading exams.

Teaching Assistant, Principles of Development. (1/99-5/00)

Department of Psychology, Washington State University, Pullman, Washington

Supervisor: Lindsey Cohen, Ph.D.

Teaching assistant for an undergraduate level class. Responsible for grading assignments and exams and delivering guest lectures. 


\section{RESEARCH EXPERIENCE}

Research Assistant, Child Health and Medical Procedures (CHAMP). (8/00-present)

Department of Psychology, West Virginia University, Morgantown, WV

Supervisor: Lindsey Cohen, Ph.D.

Assist in and develop research projects assessing and treating infant and children's negative reactions to painful medical procedures such as immunizations, chest tube pulls, and throat swabs. Also assisted in a project to increase cooperation during throat swab procedures for children with cystic fibrosis. Responsibilities include study design, supervision of undergraduate research assistants, data collection, data management, and preparing manuscripts for publication.

Research Assistant, Behavioral Medicine Lab. (7/02-6/03)

Department of Behavioral Medicine, Chestnut Ridge Hospital, Morgantown, WV

Supervisor: Richard Loren, Ph.D.

Assisted in the development of research projects evaluating the positive effects of the addition of a stress management component to a typical parent-training model for parents of children with Attention Deficit/Hyperactivity Disorder. Responsibilities included conducting literature searches, assisting in study design selection, and data collection.

Research Assistant, Developmental Disabilities Lab. (8/01-5/02)

Department of Psychology, West Virginia University, Morgantown, WV

Supervisor: Cynthia Anderson, Ph.D.

Participated in research involving the assessment and treatment of problem behaviors of children with developmental disorders. Duties included assisting with study design selection and functional analysis.

Research Assistant, Behavior Modification--Disruptive Behavior Disorders Lab. (1/01-6/02) Department of Psychology, West Virginia University, Morgantown, WV Supervisor: Cheryl McNeil, Ph.D.

Assisted in the development of research projects examining child misbehaviors and developed a coding scheme to determine the amount of time spent implementing the Level System discipline plan. Other duties included participating in study design, coding videotapes, manuscript writing, and presenting information to the lab about methodological concerns.

Research Assistant, Child Behavioral Medicine Lab. (8/99-8/00)

Department of Psychology, Washington State University, Pullman, WA

Supervisor: Lindsey Cohen, Ph.D.

Assisted in a study ("A Critical Time to Intervene: A Longitudinal Study of Infant's Fear, Anxiety, and Pain During Immunizations") of infant pain and distress during immunization procedures. Duties included coordinating research assistants, obtaining physiological measures of infant and parent distress, applying topical anesthesia (EMLA), and supervising data management and coding.

Undergraduate Research Assistant, Autism Lab. (3/98-6/99)

Department of Psychology, University of California, San Diego, San Diego, CA

Supervisors: Laura Schreibman, Ph.D. and Michelle Sullivan

Assisted in a study of the function of echolaic speech in children with autism. Duties included assisting with functional analog assessments, coding, and assisting in the administration of standardized assessments. 
Undergraduate Research Assistant, UCSD/San Diego County Dual Diagnosis Demonstration Project (9/97-6/99)

Department of Psychiatry, University of California, San Diego, San Diego, CA

Supervisor: Nancy Thomas, Ph.D.

Assisted in a three-year longitudinal treatment study looking at a comprehensive approach (e.g., medical treatment, psychological services, etc.) to treating patients with both psychiatric and substance abuse problems. Duties included co-leading a socialization group, giving standardized assessments, data entry, and participation in client case evaluations.

Undergraduate Research Assistant, Schizophrenia Thought Disorder Study. (9/97-6/98)

Department of Psychiatry, University of California, San Diego, San Diego, CA

Supervisor: William Perry, Ph.D.

Assisted in a study that examined the neuropsychology of thought disorders among geriatric patients with schizophrenia. Duties included coding of auditory tapes of schizophrenic patients and helping obtain the articles necessary for the research.

Undergraduate Research Assistant, Emotional Contagion Study. (9/97-12/97)

Department of Psychology, University of California, San Diego, San Diego, CA

Supervisors: James Kulik, Ph.D. and Christine Harris, M.A

Assisted in a study that investigated the effects of a 'worried' confederate on participants (emotional contagion). Duties included acting as the confederate.

\section{PUBLICATIONS}

Bernard, R. S., \& Cohen, L. L. (2004). Increasing adherence to cystic fibrosis treatment: A systematic review of behavioral techniques. Pediatric Pulmonology, 37, 8-16.

Bernard, R. S., Cohen, L. L., McClellan, C. B., \& MacLaren, J. E. (2004). Pediatric procedural approach-avoidance coping and distress: A multitrait-multimethod assessment. Journal of Pediatric Psychology, 29, 131-141.

Filcheck, H. A., McNeil, C. B., Greco, L. A. \& Bernard, R. S. (2004). Using a whole-class token economy and coaching of teacher skills in a preschool classroom to manage disruptive behavior. Psychology in the Schools, 41, 351-361.

McNeil, C.B., \& Bernard, R. S. (in press). Early intervention. In T. H. Ollendick \& C. S. Schroeder (Eds.) Encyclopedia of Pediatric and Clinical Child Psychology. New York: Kluwer.

Cohen, L. L., Bernard, R. S., Greco, L. A., \& McClellan, C. B. (2002). A child-focused intervention for coping with procedural pain: Are parent and nurse coaches necessary? Journal of Pediatric Psychology, 27, 749-757.

Cohen, L. L., Blount, R. L., Cohen, R. J., Ball, C. M., McClellan, C. B., \& Bernard, R. S. (2001). Children's expectations and memories of acute distress: The short- and long-term efficacy of pain management interventions. Journal of Pediatric Psychology, 26, 367-374.

Filcheck, H. A., McNeil, C. B., Greco, L. A., Ware, L. M., \& Bernard, R. S. (2001). Parent-Child Interaction Therapy: Can a manualized treatment be functional? Behavior Analyst Today, 2, 106114. 


\section{MANUSCRIPTS IN PROGRESS}

Bernard, R. S., \& Cohen, L. L. (expected submission, 8/04). Relations between parent anxiety and infant procedural distress.

Bernard, R. S., Cohen, L. L., \& Moffett, K. S. (expected submission, 8/04). Use of a token economy to increase exercise in children with cystic fibrosis.

Cohen, L. L., Bernard, R. S., McClellan, C. B., Piazza-Waggoner, C., Taylor, B. K., \& MacLaren, J. E. (in submission). Topical anesthesia versus distraction for infants' immunization distress:

Evaluation with 6-month follow-up.

Cohen, L. L., Bernard, R. S., McClellan, C. B., \& MacLaren, J. E. (in submission). Assessing Medical Room Behavior during Infants' Painful Procedures: The Measure of Adult and Infant Soothing and Distress (MAISD).

\section{INVITED SYMPOSIA/ORAL PRESENTATIONS}

Cohen, L. L., Blount, R. L., Cohen, R. J., Ball, C. M., McClellan, C. B., \& Bernard, R. S. (August, 2001). Painful medical procedures as trauma: How deep do the wounds go? In J. Faust (Chair) \& L. J. Siegel (Discussant), Trauma and Children in Health Care Settings. Symposium presented at the APA conference, Washington, D.C.

Cohen, L. L., Blount, R. L., Cohen, R. J., McClellan, C. B., Bernard, R. S., \& Ball, C. M. (August, 2000). Children's expectations and memories of acute medical distress. In D. Drotar (Chair) \& D. Faust (Discussant), Prevention and Early Intervention in Primary Care Contexts. Symposium presented at the APA conference, Washington, D.C.

\section{POSTER PRESENTATIONS}

Cohen, L. L. Bernard, R. S. Catherine B. McClellan, C. B., \& MacLaren, J. E. (November, 2004). Interactions during Infants' Injections: The Measure of Adult and Infant Soothing and Distress (MAISD). Poster to be presented at the Association for Advancement of Behavior Therapy (AABT) Convention, New Orleans, LA.

Bernard, R. S., Cohen, L. L., Moffett, K. S. (November, 2003). Use of a token economy to increase exercise in children with cystic fibrosis. Poster presented at the AABT Convention, Boston, MA.

Bernard, R. S., Cohen, L. L., Moffett, K. S., Swisher, A. K., \& Baer, L. S. (October, 2003) Increasing exercise in children with cystic fibrosis: How token economies can help. Poster presented at the North American Cystic Fibrosis Conference (NACFC), Anaheim, CA.

Bernard, R. S., Cohen, L. L., \& McClellan, C. B. (November, 2002). Parent distress, parent behavior, and infant distress during pediatric immunizations. Poster presented at the AABT Convention, Reno, NV.

Cohen, L. L., Bernard, R. S., Greco, L. A., \& McClellan, C. B. (November, 2002). Child coping, parent coaching, and nurse coaching behavior during preschoolers' immunizations. Poster presented at the AABT Convention, Reno, NV. 
Cohen, L. L., McClellan, C. B., Bernard, R. S., Piazza-Waggoner, C., Taylor, B. \& MacLaren, J. E. (November, 2002). A prospective study of topical anesthesia versus distraction for infants' procedural pain. Poster presented at the AABT Convention, Reno, NV.

Filcheck, H. A., Greco, L. A., Bernard, R. S., McNeil, C. B., Simpson, S., Fittro, E. (November, 2002). Using a whole-class token economy in a preschool classroom to manage disruptive behavior. Poster presented at the AABT Convention, Reno, NV.

McClellan, C. B., Cohen, L. L., \& Bernard, R. S. (November, 2002). Parent infant interactions during acute painful procedures. Poster presented at the AABT Convention, Reno, NV.

Bernard, R. S., Cohen, L. L., \& McClellan, C. B. (September, 2002). Infants' invasive procedures: Impact on infants and their parents. Poster presented at the 4th Biennial International Forum on Pediatric Pain, Nova Scotia, Canada.

Cohen, L. L., McClellan, C. B., Bernard, R. S., Piazza-Waggoner, C., Taylor, B. \& MacLaren, J. E. (September, 2002). Topical anesthesia versus distraction for infants' pain: A prospective analysis. Poster presented at the 4th Biennial International Forum on Pediatric Pain, Nova Scotia, Canada.

Greco, L. A., Cohen, L. L., McClellan, C. B., Bernard, R. S., \& Soliday, E. (March, 2002). Predicting perceptions of health self-efficacy: Role of trait anxiety, parenting stress, and demographic variables. Poster presented at the Anxiety Disorders Association of America National Conference, Austin, TX.

Cohen, L. L., Bernard, R. S., \& McClellan, C. B. (February, 2002). Pediatric procedural approachavoidance coping and distress: A multitrait-multimethod assessment. Poster presented at the American Association for Dental Research, Morgantown, WV.

Cohen, L. L., Bernard, R. S., \& McClellan, C. B. (November, 2001). Pediatric procedural approachavoidance coping and distress: A multitrait-multimethod assessment. Poster presented at the AABT Convention, Philadelphia, PA.

Cohen, L. L., McClellan, C. B., \& Bernard, R. S. (November, 2001). Practical behavioral interventions for infant procedural distress. Poster presented at the AABT Convention, Philadelphia, PA.

Cohen, L. L., Bernard, R. S., \& McClellan, C. B. (April, 2001). Preschoolers self-report of procedural approach-avoidance. Poster presented at the Florida Conference on Child Health Psychology, Gainesville, FL.

Cohen, L. L., McClellan, C. B., \& Bernard, R. S. (April, 2001). Infant distress by procedural phase. Poster presented at the Florida Conference on Child Health Psychology, Gainesville, FL.

Cohen, L.L., Bernard, R. S., \& McClellan, C. B. (February, 2001). Assessment of children's approachavoidance behavior during immunizations: A comparison of ratings and observations. Invited poster presented at the American Association for Dental Research, Morgantown, WV.

Cohen, L. L., McClellan, C. B., \& Bernard, R. S. (November, 2000). The impact of nurse-directed distraction on infant immunization distress. Poster presented at AABT Convention, New Orleans, LA. 
Cohen, L. L., Bernard, R. S., \& McClellan, C. B. (November, 2000). Assessment of children's approachavoidance behavior during immunizations: A comparison of ratings and observations. Poster presented at AABT Convention, New Orleans, LA.

\section{EDITORIAL EXPERIENCE}

Ad hoc co-reviewer, Behavior Therapy, (11/00)

Ad hoc co-reviewer, Children's Health Care, (1/01); (4/01); (9/01)

Ad hoc co-reviewer, Cognitive Therapy and Research, (3/01); (10/01)

Ad hoc co-reviewer, Journal of Pediatric Psychology, (4/02); (8/02)

Ad hoc co-reviewer, Mental Retardation, (2/02)

Ad hoc co-reviewer, Pediatric Pulmonology, (3/03) 


\section{REFERENCES}

Lindsey L. Cohen, Ph.D.

Assistant Professor

West Virginia University

Department of Psychology

2220 Life Sciences Building

P.O. Box 6040

Morgantown, WV, 26506-6040

(304) 293-2001 ext. 31644

Lindsey.Cohen@mail.wvu.edu

Kevin T. Larkin, Ph.D.

Professor

West Virginia University

Department of Psychology

2220 Life Sciences Building

P.O. Box 6040

Morgantown, WV, 26506-6040

(304) 293-2001 ext. 31668

Kevin.Larkin@mail.wvu.edu
Cheryl B. McNeil, Ph.D.

Associate Professor

West Virginia University

Department of Psychology

2220 Life Sciences Building

P.O. Box 6040

Morgantown, WV, 26506-6040

(304) 293-2001 ext. 31677

Cheryl.McNeil@mail.wvu.edu

Cheryl Rode, Ph.D.

Assistant Training Director

Sharp HealthCare

Psychology Services

Sharp Mesa Vista Hospital

7850 Vista Hill Ave.

San Diego, CA 92123

(858) 694-8357

Cheryl.Rode@sharp.com

Tandy J. McClung, Ed.D.

Assistant Professor

West Virginia University

Department of Behavioral Medicine and Psychiatry

930 Chestnut Ridge Road

Morgantown, WV, 26505-2854

(304) 293-2411

tmcclung@hsc.wvu.edu 